Enrique Samanamud Valderrama*

Universidad de Lima, Instituto de Investigación Científica, Lima, Perú

Recibido: 6 de marzo de 2017 Concepto de evaluación: 5 de abril de 2017

Aprobado: 25 de mayo de 2017

Artículo de investigación

(C) 2017 Universidad Católica de Colombia. Facultad de Ciencias

Económicas y Administrativas. Todos los derechos reservados

* Economista, MBA y Máster en Administración Financiera y Hacienda Pública. Profesor de los cursos de Economía del Bienestar y Finanzas Públicas y Coordinador del Área de Política Económica, Facultad de Economía, Universidad de Lima. Correo electrónico: csamana@ulima.edu.pe
Finanz. polit. econ., ISSN: 2248-6046, Vol. 9, No. 2, julio-diciembre, 2017, pp. 265-299

http://dx.doi.org/10.14718/revfinanzpolitecon.2017.9.2.4

\section{Análisis de equidad horizontal de las transferencias fiscales en el Perú*}

\section{RESUMEN}

El presente artículo analiza la equidad horizontal de las transferencias fiscales en el Perú. Para ello, primero, se desarrolla el marco teórico sobre las transferencias fiscales; luego se detalla la clasificación actual de las transferencias fiscales en el Perú según el presupuesto público 2013. De igual manera, se define un modelo de reclasificación de dichas transferencias, con el cual se evalúa si dicha distribución, desde una perspectiva de equidad horizontal, responde a una que equilibre el nivel de necesidades de bienes y servicios públicos de la jurisdicción con los recursos transferidos.

Palabras clave: descentralización fiscal, transferencias fiscales, efecto papel matamoscas, índice de desigualdad, recursos ordinarios, recursos determinados.

JEL: H71

\section{Horizontal equity analysis of fiscal transfers in Peru}

\section{ABSTRACT}

This article analyzes the horizontal equity of fiscal transfers in Peru. To this effect, the theoretical framework of fiscal transfers is presented first, followed by a description of the current classification of fiscal transfers in Peru according to the 2013 public budget. Similarly, a reclassification model of these transfers is developed to assess whether such distribution, from a horizontal equity perspective, would balance the necessity level of public goods and services in its jurisdiction with the transferred resources.

Keywords: fiscal decentralization, fiscal transfers, flypaper effect, inequality index, ordinary resources, determined resources.

\footnotetext{
* El presente artículo forma parte de una investigación más amplia sobre el análisis de la heterogeneidad vertical y horizontal de las transferencias fiscales en el Perú, realizada por el autor para el Instituto de Investigación Científica (IDIC) de la Universidad de Lima entre 2014 y 2015, la cual contó con el apoyo de los asistentes de investigación Diego Palomino B. y Luis Peralta P.
} 


\section{Análise de equidade horizontal das transferências fiscais no Peru}

\section{RESUMO}

O presente artigo analisa a equidade horizontal das transferências fiscais no Peru. Para isso, primeiro, é desenvolvido o marco teórico sobre as transferências fiscais; depois é detalhada a classificação atual das transferências fiscais no Peru segundo o orçamento público de 2013. Da mesma forma, é definido um modelo de reclassificação de ditas transferências, com o qual é avaliada a dita distribuição, desde uma perspectiva de equidade horizontal, responde a uma que equilibre o nível de necessidades de bens e serviços públicos da jurisdição com os recursos transferidos.

Palavras-chave: descentralização fiscal, efeito flypaper, índice de desigualdade, recursos determinados, recursos ordinários, transferências fiscais. 


\section{INTRODUCCIÓN}

Las transferencias pueden ser definidas como un traspaso de recursos fiscales entre niveles de gobierno (compensación), generalmente del Gobierno Nacional a un gobierno subnacional, y se sustentan en dos importantes principios: suficiencia y nivelación. Ambos principios se derivan de la búsqueda de la sostenibilidad financiera aplicada a los sistemas subnacionales, referida a que cada gobierno subnacional debe tener capacidad fiscal de obtener ingresos para financiar su gasto y el cumplimiento de su deuda. Aunque no es extraña la transferencia de recursos entre gobiernos subnacionales (solidaridad), ello no es lo usual, especialmente en sistemas políticos unitarios.

El principio de suficiencia recaudatoria asegura que los gobiernos subnacionales dispongan de los recursos suficientes para atender la prestación de los servicios asumidos dentro del marco de sus competencias. Esta suficiencia está referida, entonces, en sentido amplio, a la igualdad entre los ingresos no financieros y los gastos no financieros, y se puede medir por el cociente entre ambos. Cuando existe igualdad en los índices de cada nivel de gobierno, se da una situación de equilibrio vertical' ${ }^{\text {. }}$.

El principio de nivelación o igualación, por su parte, también se interesa por el equilibrio financiero pero de carácter horizontal, lo cual busca la igualdad de trato entre iguales, en la idea de que para la misma carga fiscal debe darse igual nivel de provisión de bienes y servicios públicos, con independencia del lugar de residencia; es decir, que se nivele el "beneficio fiscal neto" de los ciudadanos de las diferentes jurisdicciones, ya que de lo contrario se estaría generando una mala distribución de los recursos productivos del país. A diferencia del principio anterior, donde los términos de referencia eran los ingresos no financieros versus los gastos

$1 \quad$ Si se asume que el equilibrio financiero también contempla la autonomía fiscal, ligada principalmente a la asignación de tributos vista, en sentido estricto, el equilibrio vertical solo debería considerar los ingresos provenientes de su poder fiscal exclusivo. no financieros, aquí los términos de referencia son los niveles de provisión y la presión fiscal.

En tal sentido, al hablar de las transferencias basadas en el principio de suficiencia, puede decirse que son transferencias de nivelación vertical, y cuando se basan en el principio de nivelación, se habla de transferencias de nivelación horizontal. Cuando ambos principios son integrados en una sola propuesta de transferencia, se denominan transferencias de integración o integradas. Aunque se deduce fácilmente la definición de cada una de ellas, no está de más señalar que, en un sistema vertical, las transferencias corren a cuenta del Gobierno Nacional; en cambio, en las transferencias horizontales, corren a cuenta de los gobiernos subnacionales.

Aun cuando la autonomía fiscal de los gobiernos subnacionales -medido como la participación de los ingresos propios en el total de ingresos- varía enormemente, se constata que existe cada vez más un aumento de responsabilidades en el área de gasto que es asumido por los gobiernos subnacionales. Adicionalmente, la insuficiencia de bases fiscales de considerable rendimiento ha hecho que los ingresos se encuentren estancados o incluso hayan disminuido, aumentando así la brecha entre los porcentajes de participación del gasto y el ingreso de los propios gobiernos subnacionales ${ }^{2}$.

Estos dos aspectos, crecimiento de los gastos y estancamiento de los ingresos propios, aunados a la reticencia de los gobiernos nacionales para aumentar el tamaño de las bases y al deseo de reducir los desequilibrios horizontales, son algunas de las razones que han generado que los gobiernos subnacionales se vuelvan más dependientes del Gobierno Nacional en cuanto a transferencias.

A pesar de todas estas razones, es importante no abusar del uso de este esquema, puesto que los ciudadanos pierden de vista la relación existente entre el cobro de los tributos y el costo de los servicios públicos que reciben, tras lo cual se genera

2 Incluso en los sistemas más desarrollados, donde las responsabilidades están bien definidas, surgen dificultades cuando los gobiernos nacionales transfieren tareas sin los recursos correspondientes (unfunded mandates). 
desinterés por la rendición de cuentas, abuso en el uso de los servicios, entre otros aspectos.

Para autores como Polèse (1998), incluso el efecto acumulado engendrado por los pagos de transferencia es la creación de lo que algunos llaman el "síndrome de la dependencia", cuyas características son:

a) Una población acostumbrada a vivir de la generosidad del Estado.

b) Industrias que cuentan con obtener subvenciones del Estado.

c) Gobiernos subnacionales que dependen del Gobierno Nacional para su financiamiento.

\section{MARCO TEÓRICO SOBRE LAS TRANSFERENCIAS FISCALES}

El marco de análisis referencial sobre las transferencias se circunscribe al cuerpo teórico de la economía del bienestar, disciplina normativa que se mueve entre los conceptos muchas veces contradictorios de eficiencia y equidad. Por ello, la teoría no es suficiente para definir un sistema ideal de transferencias, porque los objetivos pueden ser conflictivos, y los investigadores - aún más los encargados de la política pública - tienen visiones posiblemente influenciadas por percepciones políticas, económicas y sociales que los lleva a un balance de objetivos de una forma distinta. Por ejemplo, la necesidad de las transferencias está directamente relacionada con el grado de descentralización, y si bien la mayor parte del cuerpo teórico establece que la descentralización contribuye a la eficiencia en la oferta de programas fiscales, también puede generar violaciones a la eficiencia y la equidad en la economía nacional.

De igual forma, el solo hecho de plantearse mayor equidad como un objetivo prioritario puede tener diferentes acepciones y expresarse de diferente forma en el diseño de las transferencias; por último, solo desde un punto de vista de la eficiencia, el grado de institucionalidad de un país puede favorecer el nivel y la adopción de un tipo de transferencias sobre otros.

Esta discusión sugiere que no existe un conjunto "óptimo" de transferencias intergubernamentales que se ajuste a todas las circunstancias; por el contrario, las transferencias tienen que ser hechas a la medida de cada caso, dependiendo de los objetivos deseados, las condiciones iniciales y las limitaciones de recursos.

\section{Clasificación de las transferencias fiscales}

Las transferencias pueden ser objeto de diferentes tipos de clasificación, aunque mayoritariamente la literatura acepta las que se presentan en la figura 1.

a) Transferencias condicionadas o específicas (earmarked grants). El gobierno donante (GD) especifica el uso que debe darse a dichos recursos transferidos; en otras palabras, se concede al gobierno beneficiario $(\mathrm{GB})$ bajo condición o con la obligación de ser usada solamente para un propósito específico, ya sea que se trate de gastos corrientes, gastos de capital o ambos, es decir, donde su uso esté "amarrado" al propósito o las condiciones del financiamiento. También se les conoce como transferencias específicas o selectivas.

A su vez, las transferencias condicionadas pueden ser obligatorias (mandatory grants) o discrecionales (discretionary grants). Las obligatorias son aquellas que se establecen a través de un mandato legal, basadas en normas que impone el gobierno que establece la transferencia. Por su parte, las discrecionales se caracterizan porque tanto su importe como las condiciones bajo las que se establecen no se determinan por normas, sino por criterios ad hoc o discrecionales. 
Figura 1.

Tipología de las transferencias fiscales

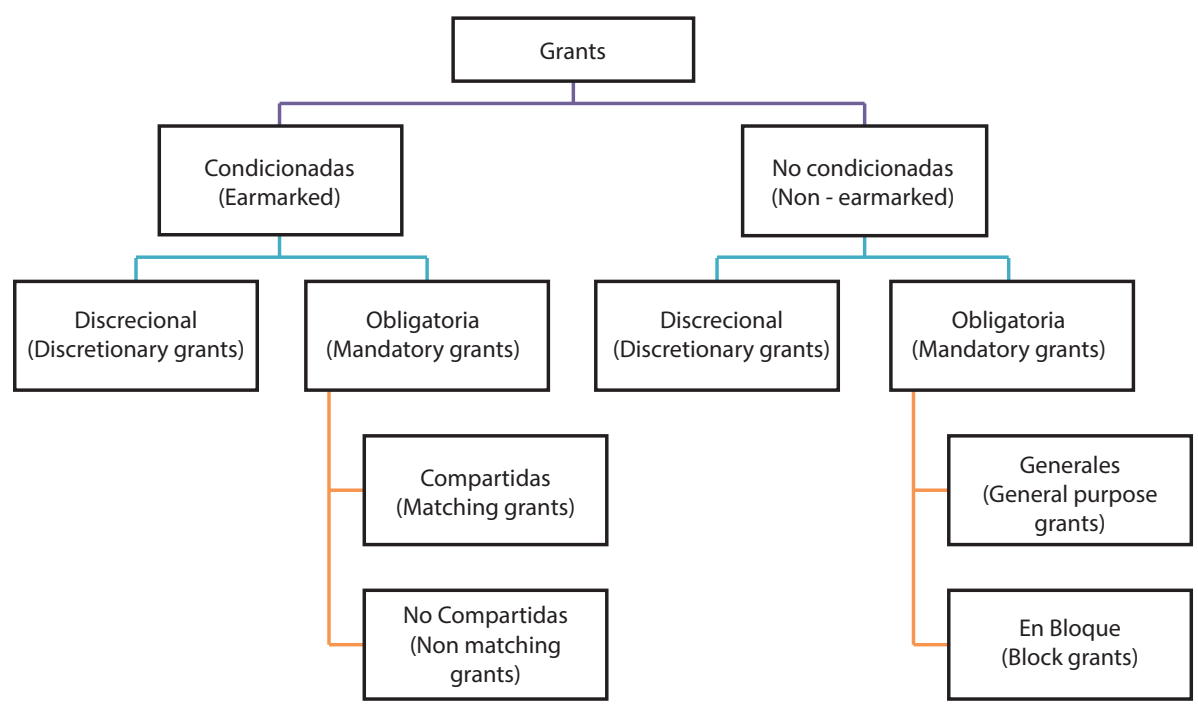

Fuente: OECD

Las transferencias condicionadas obligatorias pueden ser compartidas (matching grants) o no compartidas (non -matching grants). Las primeras complementan la contribución que efectuarán los GD; por ello, dependen del gasto real o normativo en la provisión de bienes y servicios para los que se condicionan, o bien, de la recaudación afectada a estos. Dicho de otra forma, son aquellas donde la aportación del GD representa un porcentaje de la aportación del GB. Tal aportación porcentual puede ser abierta o tener un límite máximo de financiamiento por parte del GD.

Todas las otras transferencias condicionadas y obligatorias que no se conceden como complementarias a recursos aportados del GB son no compartidas. En este sentido, una transferencia que se condicione obligatoriamente al cumplimiento de unas metas de gasto o de recaudación, pero que no sean objeto de contribución complementaria por parte del GB, debe ser considerada simplemente como no compartida.

b) Transferencias no condicionadas (non earmarked grants). Aquellas que pueden ser gastadas por los GB como si de sus propios recursos tributarios se tratase, es decir, donde el GD no impone ninguna restricción de uso y el GB puede decidir libremente sobre el destino de los fondos. También se les conoce como transferencias no selectivas.

A su vez, las transferencias no condicionadas pueden ser obligatorias (mandatory grants) o discrecionales (discretionary grants). Los conceptos en este caso son los mismos que cuando se trata de condicionadas, es decir, las obligatorias, que se establecen a través de un mandato legal, y las discrecionales, que se establecen por criterios ad hoc.

Las transferencias no condicionadas obligatorias pueden ser generales 
(general porpuse grants) o en bloque (block grants). Ambas son para finalidades similares y coinciden en que aumentan los recursos de los GB sin cambiar los costos en la provisión de los servicios. La diferencia estriba en que la transferencia en bloque se otorga para ofrecer un respaldo general en un área específica de gasto subnacional (como salud o infraestructura vial), pero permite que los GB definan su asignación a los proyectos específicos. Sin embargo, en la práctica, esta diferencia desaparece en la medida en que, por ser no condicionadas, su uso no está controlado, aunque en ocasiones se amarra al cumplimiento de un estándar mínimo que ha de ser alcanzado por el GB.

Otro tipo de clasificación propuesta por Alvarado (2003, p. 15) las agrupa de acuerdo con diversos criterios, como el uso de fondos, su distribución, su fuente, el grado de intervención del gobierno beneficiario y la existencia de contrapartidas (tabla 1).

Tabla 1.

Otra tipología de transferencias

\begin{tabular}{|c|c|}
\hline Criterio & Tipo de transferencias fiscales \\
\hline Uso de fondos & $\begin{array}{ll}\text { - } & \text { Sin restricciones } \\
\text { - } & \text { Con algunas restricciones } \\
\text { - } & \text { Bloque o sectorial } \\
\text { - } & \text { Categórica o específica }\end{array}$ \\
\hline $\begin{array}{l}\text { Distribución de } \\
\text { fondos }\end{array}$ & $\begin{array}{ll}\text { - } & \text { Devolutivas } \\
\text { - } & \text { Con fórmula } \\
\text { - } & \text { Por solicitud y competitividad } \\
\text { - } & \text { Decisiones discrecionales }\end{array}$ \\
\hline Fuente de fondos & $\begin{array}{l}\text { - } \quad \text { Participación de un impuesto } \\
\text { - } \quad \text { Reembolso de gastos aprobados } \\
\text { - } \quad \text { Decisiones discrecionales }\end{array}$ \\
\hline $\begin{array}{l}\text { Intervención en la } \\
\text { toma de decisiones } \\
\text { del receptor } \\
\text { (subnacional) }\end{array}$ & $\begin{array}{ll}\text { - } & \text { Ninguna } \\
\text { - } & \text { Supervisión administrativa } \\
\text { Supervisión técnica }\end{array}$ \\
\hline $\begin{array}{l}\text { Contrapartida en } \\
\text { el monto y tiempo } \\
\text { disponible }\end{array}$ & $\begin{array}{l}\text { - } \quad \text { Sin contrapartida } \\
\text { - Con contrapartida, con límite en } \\
\text { el monto o tiempo asignado } \\
\text { - Con contrapartida, sin límite en } \\
\text { el monto o tiempo asignado }\end{array}$ \\
\hline
\end{tabular}

Fuente: Alvarado (2003).
El tipo de transferencia que se establezca puede tener efectos muy diferentes. Albi, GonzálezPáramo y Zubiri (2004) mencionan que si el objetivo de una transferencia es estimular un gasto público concreto (eficiencia en gasto), lo correcto es que fuera condicional y compensatoria; pero si el objetivo es incrementar el bienestar en la jurisdicción (equidad interjurisdiccional), en general son preferibles las transferencias incondicionales.

Sin embargo, es cierto también que el efecto de la condicionalidad puede ser engañoso en algunos casos, debido a que un gobierno subnacional puede gastar la transferencia en la función o el programa establecidos por el Gobierno Nacional $y$, por tanto, cumplir con la condicionalidad; pero, al mismo tiempo, puede reducir el gasto que anteriormente estaba financiando con sus propios recursos en la misma partida. Por consiguiente, la efectividad de las transferencias condicionales solo debe evaluarse en términos del objetivo de asegurar un monto mínimo de gasto en la función o el programa que el Gobierno Nacional desea impulsar.

La literatura sobre financiación pública también hace hincapié en la necesidad de generar esquemas de transferencias que no sean rígidos, ya que ello impide luego efectuar los ajustes fiscales necesarios que permitan amortiguar los efectos de shocks recesivos en la economía mundial, como demuestra la experiencia internacional. Por otro lado, se observa un gran interés por establecer mecanismos de transferencia que consideren los problemas de desequilibrio fiscal vertical y horizontal, externalidades, economías de escala en favor de la administración de tributos en el ámbito nacional, entre otros.

Según Aghón (1999, p. 20), se deben desvincular las transferencias de los tributos nacionales y determinarlas en función de cuatro criterios fundamentales:

a) Población destinataria.

b) Costos reales de la prestación de los servicios.

c) Eficiencia en su prestación.

d) Capacidad y esfuerzo fiscal de los gobiernos territoriales. 
Lo importante de todo esquema de transferencias es que debe permitir un equilibrio entre eficiencia y equidad en la distribución de los recursos. Allí se encuentra el reto de los próximos años para las economías latinoamericanas.

\section{Efectos de las transferencias fiscales}

Desde el punto de vista puramente económico, las transferencias son un traslado de recursos a los gobiernos subnacionales, los cuales se convierten en agentes beneficiarios que toman decisiones públicas de gasto sobre dichos recursos, con la única finalidad, en términos teóricos, de aumentar el bienestar de los ciudadanos de su circunscripción. Para efectos prácticos, además se asume que todos los ciudadanos de la circunscripción son iguales; por tanto, puede prescindirse de las diferencias en los gustos y las preferencias de cada uno de ellos, así como de la problemática de cómo agregar dichas preferencias socialmente. De igual manera, no existe una conducta oportunista en los que llevan a cabo las políticas públicas, es decir, no existen otros objetivos ocultos que generen externalidades entre ellos.

La forma como afecte el comportamiento del GB depende del tipo de transferencia de que se trate. Así, siguiendo a Shah (1994a, 1994b,2006), en el gráfico 1 se puede observar el efecto de las transferencias no condicionadas, que simplemente aumentan los recursos del GB y trasladan su restricción de presupuesto de la original $A B$ hacia la derecha y arriba, en forma paralela hasta $C D$; las distancias $A D$ y $B C$ representan las magnitudes equivalentes de subvención $(A D=B C)$. La transferencia no afecta los precios relativos, lo que significa que no hay un efecto sustitución, sino solo un efecto de ingreso puro. Dicho incremento de recursos puede disponerse en cualquier combinación de bienes y servicios públicos que aumente el bienestar, o bien, ser usada para ofrecer un alivio tributario a los habitantes de su circunscripción territorial, lo que en teoría debiera tener el mismo efecto.
Gráfico 1

Efecto de las transferencias no condicionadas

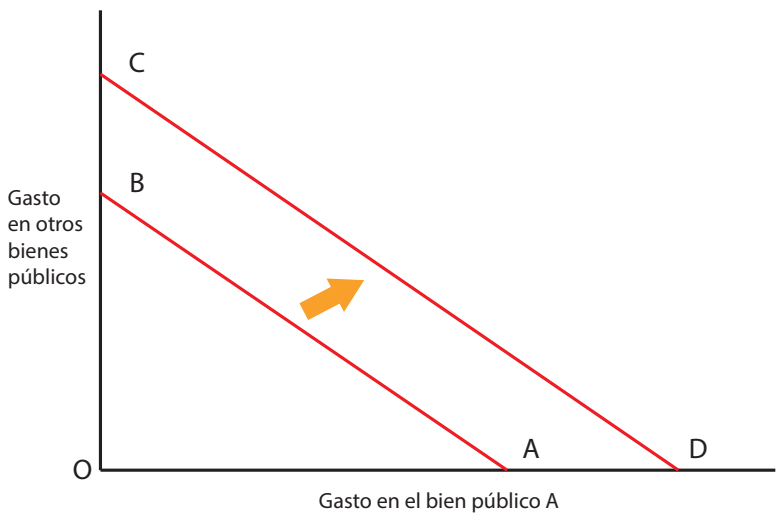

Fuente: Shah (1994).

Sin embargo, como la abundante literatura empírica ha demostrado (Gramlich, 1977; Inman, 1979; Fisher 1982; Hines y Thaler, 1995; Oates, 1999; Rosen, 2002, entre otros), una reducción impositiva no tiene el mismo efecto que una transferencia equivalente de la misma magnitud sobre la función de ingresos de los ciudadanos. Esto significa que el dinero de una subvención tiende a quedarse donde llega primero, dejando una fracción menor de lo esperado disponible para el alivio en impuestos; este es el fenómeno conocido como efecto del papel matamoscas (flypaper effect).

La implicancia es que las transferencias a los GB tienden a generar más gasto local del que se observaría si se hubiese hecho la misma transferencia directamente a los residentes locales por la vía de una reducción impositiva; es decir, las transferencias elevan el gasto final de forma más que proporcional en los servicios públicos que financian, y no se traduce en reducciones impositivas o gastos en otros servicios en la misma magnitud.

Se han intentado varias explicaciones de este efecto, entre ellas, que los gestores públicos buscan maximizar el tamaño de sus presupuestos por razones políticas y burocráticas, ya que al hacerlo les da mayor poder e influencia en la comunidad, y los votantes no perciben -al menos de inmediato- el verdadero precio marginal del gasto público (costo marginal mayor al costo medio; 
Stiglitz, 2000, pp. 669-670). Otras explicaciones tienen que ver más con la especificación incorrecta de la función de producción de bienes públicos que brinda el GB.

Por su parte, el efecto de las transferencias condicionadas depende de si el GB debe compartir dicha finalidad de gasto. Como se observa en el gráfico 2, si no existe obligación de efectuar una compensación para la provisión del bien público $A$, entonces la transferencia desplaza la restricción presupuestal de $A B$ a $C D$ y la acota hasta el punto $C^{\prime}$, donde al menos $\mathrm{OE}=\mathrm{BC}^{\prime}$, que representa la cantidad de bien público financiado que se adquirirá.

Gráfico 2 .

Efectos de las transferencias condicionadas no compartidas

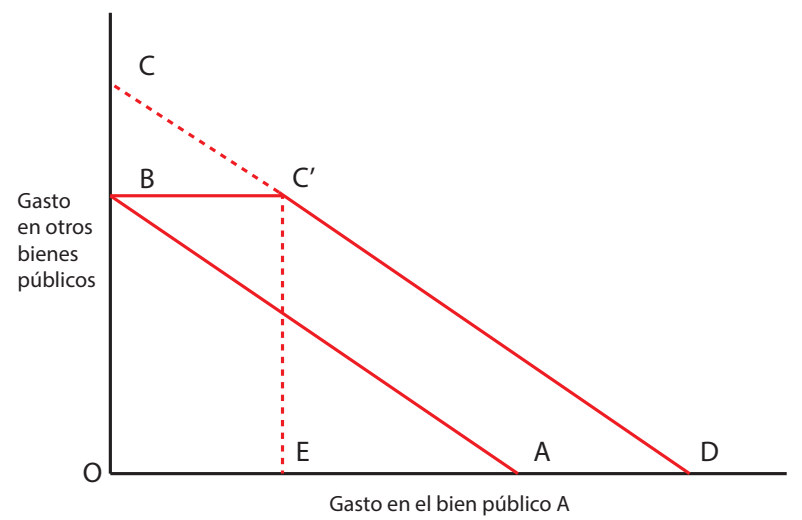

Fuente: Shah (1994).

En este caso, el efecto sustitución también es nulo, al igual que una transferencia no condicionada, en la medida en que el volumen total de gastos en el bien público financiado sea menor que la cantidad que los ciudadanos de la circunscripción desean gastar en él, y en ese sentido no resulta ineficiente. Puede haber situaciones en las cuales las preferencias por el bien público $A$ para los ciudadanos sea inferior al volumen de gasto financiado (en algún punto entre $\mathrm{OE}$ ); sin embargo, si el bien público es preferente o tiene alguna prioridad estratégica para el GD, con este tipo de transferencias es posible realizarlos, por lo cual se debe estar preparados para sacrificar algo de satisfacción de los ciudadanos receptores a cambio de asegurar que los fondos sean dirigidos a dichos gastos.

Por su parte, si la transferencia condicionada obliga al GB a compartir el gasto en un porcentaje sin límite máximo de financiación (gráfico 3), entonces la restricción presupuestaria $A B$ gira en sentido inverso de las manecillas del reloj y la nueva línea presupuestal sería $\mathrm{BD}$, con un intercepto superior que denota la posibilidad de consumir más del bien público financiado $A$. En este caso, existiría un efecto sustitución, dado que se reduce el precio relativo de la provisión del bien público $\mathrm{A}$ respecto de los otros bienes, lo que aumenta su consumo en detrimento del consumo de los otros bienes a partir de un presupuesto dado. Sin embargo, también existe un efecto ingreso, dado que dicha financiación de los GD aumenta el presupuesto total del GB y permite que se pueda adquirir más de otros bienes y servicios públicos, aunque sean relativamente más costosos, como en el punto sobre la línea presupuestaria BD.

Gráfico 3.

Efectos de las transferencias condicionadas compartidas (sin límite de financiación)

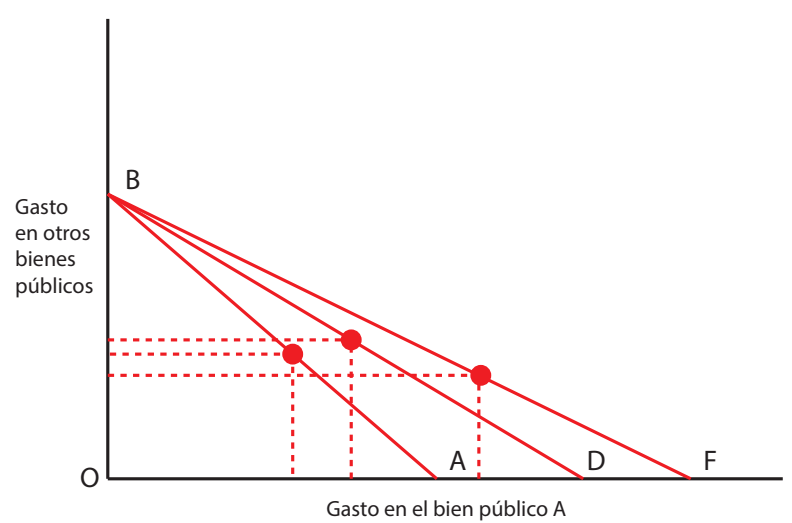

Fuente: Shah (1994).

Normalmente, la evidencia empírica demuestra que el efecto ingreso domina al efecto sustitución y se logra proveer más de ambos tipos de bienes; es decir, el gasto en el área específica aumenta en menos de la cantidad de la subvención, en cuyo caso el monto restante va a otros bienes y servicios públicos y alivios impositivos, a lo cual se denomina efecto de intercambiabilidad o desvío de fondos (fungibility 
effect) en las subvenciones (Broadway y Shah, 2009); sin embargo, es posible que si el efecto sustitución es superior al efecto ingreso, pueda haber una reducción en el consumo de los otros bienes públicos. Ello tiene más probabilidades de ocurrir cuando el bien tiene mayor prioridad relativa de gasto o, por ejemplo, cuando el porcentaje de financiación del GD es mayor, como en el punto de equilibrio sobre la línea presupuestaria BF.

En vista de que este tipo de transferencias altera la relación de precios, se considera menos eficiente que los anteriores esquemas; sin embargo, corrige otro tipo de ineficiencias que surgen por el efecto de diseminación de beneficios o externalidades, es decir, de la tendencia a subofrecer el bien público cuando es posible que miembros de otros gobiernos subnacionales también se beneficien de ellos, sin participar en su financiación.

Situación distinta ocurre si la financiación del GD tuviera un límite máximo, dado que, en ese caso, además del mayor control que tiene sobre su presupuesto, corrige parcialmente las ineficiencias generadas por este tipo de transferencia. Como se observa en el gráfico 4, la financiación compartida con límite máximo altera la relación de precios, pero solo respecto al volumen por ser financiado; a partir de allí, la relación de precios vuelve a ser la misma, como se observa en la nueva línea presupuestaria BFD.

Gráfico 4.

Efecto de las transferencias condicionadas compartidas (con límite de financiación)

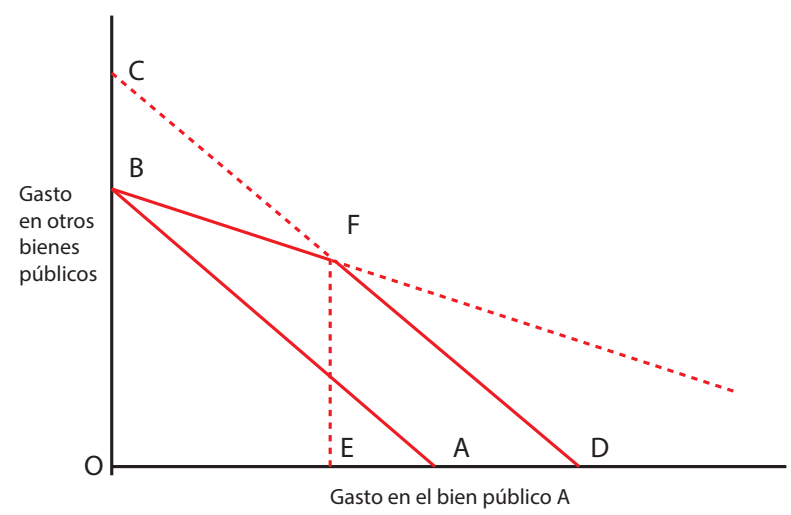

Fuente: Shah (1994).
Si lo que se busca es inducir a los niveles inferiores de gobierno a incrementar el gasto en la función financiada, entonces las subvenciones condicionadas compartidas sin límite de financiación son las más apropiadas; pero si el objetivo es simplemente mejorar el bienestar de los ciudadanos locales, sería preferible una transferencia para propósitos generales sin compensación, ya que preservan la autonomía local.

\section{Taxonomía de las transferencias fiscales en el Perú}

La primera pregunta que surge a partir del análisis teórico es: ¿cuál es la taxonomía de las transferencias fiscales en el Perú?, lo cual implica primero definir qué es lo que se entiende por transferencia. El Manual de Estadísticas de las Finanzas Públicas (MEFP) del Fondo Monetario Internacional (FMI, 2014) define una transacción de este modo:

Una interacción entre dos unidades institucionales 3 por mutuo acuerdo, o una acción dentro de una unidad que a efectos analíticos conviene tratar como una transacción, y que puede ser un intercambio o bien una transferencia. Una transacción es una transferencia si una unidad suministra un bien, un servicio, un activo o mano de obra a una segunda unidad sin recibir simultáneamente a cambio un bien, un servicio, un activo o mano de obra.

En la estructura de los ingresos fiscales de cualquier país existen recursos que se agrupan como "donaciones y transferencias", lo cual comprende recursos financieros voluntarios no reembolsables de tres fuentes reconocidas en el Sistema de Estadísticas de las Finanzas Públicas. Como son: 1. Las donaciones de gobiernos extranjeros.

3 Una unidad institucional es una entidad económica que tiene capacidad, por derecho propio, de poseer activos, incurrir pasivos y realizar actividades económicas y transacciones con otras entidades, tales como las unidades gubernamentales, corporaciones, instituciones sin fines de lucro, cuasi corporaciones y hogares. 
2. Las donaciones de organismos internacionales.

3. Las donaciones de otras unidades del Gobierno General.

En el caso peruano deben distinguirse los dos primeros tipos de donaciones del tercero, porque este último (las donaciones provenientes de otras unidades del Gobierno General), según el MEFP del FMI, se elimina en la consolidación cuando se compilan estadísticas para el sector de Gobierno General, de forma que solo aparezcan las donaciones provenientes de gobiernos extranjeros y organismos internacionales; además, solo son necesarias si se compilan estadísticas para un subsector del sector Gobierno General.

Respecto de los impuestos compartidos o cedidos $^{4}$, en relación con las transferencias entre niveles de gobierno, en la literatura no existe un criterio único para definirlas, y la línea que separa ambas definiciones no está trazada de manera uniforme entre los países o a lo largo del tiempo (Blöchliger y Petzold, 2009). Las reglas establecidas en publicaciones como las de Cuentas Nacionales de las Naciones Unidas o las Estadísticas de las Finanzas Públicas del FMI proporcionan una orientación incompleta sobre el tema; por tanto, suelen confundirse mucho ambos conceptos y constituyen dos fuentes de financiación en el ámbito subnacional difíciles de separar.

Ello se profundiza, por un lado, porque muchas fórmulas para compartir impuestos se han ido complicando progresivamente, rompiendo el vínculo entre lo que se genera en el territorio de cada gobierno subnacional, lo que se envía a la caja única ${ }^{5}$ lo que finalmente recibe nuevamente

4 Se refiere a la descentralización de la recaudación (coparticipación), es decir, a la cesión total o parcial a un nivel de gobierno del rendimiento sobre ciertos tributos, que dependen de las decisiones de otro nivel de gobierno. Así, el rendimiento de un tributo puede ser compartido por diferentes niveles de gobierno, pero el gobierno subnacional no tiene competencia normativa y la administración tributaria se encomienda al Gobierno Nacional.

5 Constituida por la cuenta principal de la Dirección Nacional del Tesoro Público, las otras cuentas bancarias de las cuales es titular y todas las cuentas bancarias donde se manejen fondos públicos, independientemente de la fuente de financiamiento y de su titular, con excepción del Seguro Social de cada nivel de gobierno. Por otro lado, reformas de tipo político han hecho que algunas transferencias intergubernamentales se parezcan más bien a una participación en la recaudación de impuestos en el ámbito nacional; por ello, lo que se contabiliza como tributos compartidos en un país puede hacerse como transferencias intergubernamentales en otro. Incluso en algunos países, diferentes departamentos del Gobierno Nacional han adoptado distintos puntos de vista sobre cómo clasificar los acuerdos relativos a los ingresos de los gobiernos subnacionales.

Según el título B de Clasificación y Registro del Ingreso, numerales 5.24 al 5.27 del propio Manual MEFP, si una unidad del gobierno es responsable del recaudo de ciertos impuestos que luego son transferidos a otra unidad del gobierno, dichos impuestos pueden registrarse como ingreso tributario de la unidad recaudadora, o bien, pueden reasignarse como ingreso tributario de la unidad receptora, siempre que esta unidad cumpla con las siguientes condiciones:

a) Tenga la autoridad para aplicar el impuesto, aunque sea de forma delegada.

b) Pueda establecer y modificar su tasa impositiva.

c) Pueda determinar, a su discreción, el uso de los recursos, tan solo actuando el gobierno recaudador como un agente del gobierno receptor.

En este caso, el MEFP recomienda:

Cualquier cantidad retenida por el gobierno recaudador como cargo por la recaudación debe tratarse, como pago por un servicio o tratarse, por ejemplo, en el marco de un arreglo de coparticipación de impuestos, como una donación corriente. [En cambio,] [...] si se delegó al gobierno recaudador la autoridad para establecer $y$ modificar la tasa, así como para decidir sobre el uso final de los recursos, entonces las cantidades recaudadas deben tratarse

Salud (ESSALUD) y de aquellas entidades constituidas como personas jurídicas de derecho público y privado facultadas a desarrollar la actividad empresarial del Estado. 
como ingresos tributarios de este gobierno. Por otra parte, si diferentes gobiernos establecen conjuntamente y por igual la tasa de un impuesto y la distribución de los recursos, sin que ninguno de ellos tenga la autoridad final y exclusiva, entonces los ingresos tributarios se atribuyen a cada gobierno según la proporción que le corresponda de los recursos. Si el arreglo permite a una unidad del gobierno ejercer el control final y exclusivo, entonces todos los ingresos tributarios se atribuirán a dicha unidad. [...] Si un gobierno tiene la autoridad constitucional o de otra índole de aplicar un impuesto, pero que otros gobiernos establezcan individualmente la tasa del impuesto en sus jurisdicciones y decidan individualmente el uso de los recursos generados por los impuestos. En este caso, los recursos generados por los impuestos en cada jurisdicción de gobierno respectiva se atribuyen como ingresos tributarios de dicho gobierno. (FMI, 2014)

\section{CLASIFICACIÓN Y RECLASIFICACIÓN DE LAS TRANSFERENCIAS FISCALES EN EL PERÚ}

En el caso peruano, muchos de los recursos que reciben los gobiernos subnacionales provienen de los llamados recursos determinados, esto es, ingresos tributarios y no tributarios cedidos, de los cuales participan los gobiernos subnacionales con muy poca autonomía fiscal. En tal sentido, siguiendo la definición del FMI, se van a considerar como transferencias todos los recursos determinados. Finalmente, se encuentran los recursos ordinarios: en sentido estricto, transferencias del gobierno nacional, que algunas veces se realizan directamente a proyectos de inversión o a diversos programas sociales administrados por los gobiernos subnacionales. En otros casos, se efectúan indirectamente a través de diversos fondos, como es el caso del Fondo de Compensación Regional (FONCOR).
Con respecto a la base de registro de las cuentas, el MEFP recomienda que los flujos de gastos e ingresos deben registrarse sobre la base del devengado, debido a que, "si bien en este caso el momento de registro no coincide con el momento del flujo efectivo de recursos, es cuando se crea, transforma, intercambia, transfiere o extingue valor económico, independientemente de que se hayan efectuado o esten pendientes el cobro o el pago de efectivo". Por consiguiente, la base del devengado es la mejor forma de estimar el impacto macroeconómico de la política fiscal.

A efectos de analizar la heterogeneidad de los gobiernos subnacionales, en este estudio se flexibilizará la definición formal de transferencia: de manera general, se establecerá como toda fuente que proviene de un nivel superior de gobierno; esto incluye, para el caso del Perú, los recursos ordinarios, los recursos determinados y las transferencias intergubernamentales que figuran en el rubro de donaciones y transferencias.

Para formalizar esta idea, en lo que sigue se procederá a delimitar en mayor detalle cada una de las cuentas presupuestales que se presentan en el portal de Transparencia Económica del Ministerio de Economía y Finanzas de Perú (MEF), siguiendo algunos criterios generales y específicos recogidos internacionalmente. Asimismo, se realizarán algunos ajustes a la información para su mejor evaluación de acuerdo con el objetivo buscado en el presente estudio.

\section{Delimitación de la periodicidad, unidades institucionales y transacciones}

Estos aspectos han sido pertinentes de ser considerados y reclasificados en esta investigación:

a) Respecto de la periodicidad, para el análisis se ha tomado la información disponible para el ejercicio fiscal 2013 en forma anual, por ser este de tipo cerrado completamente y presentado al Congreso de la República en la Cuenta General de la República (CGR). Cabe agregar además 
que, a partir del ejercicio 2003, el PBI real del Perú tuvo un crecimiento sostenido promedio de $6,2 \%$, el cual alcanzó su máximo nivel con una tasa de $9,2 \%$ en el 2008, que se detuvo en el 2009 luego del estallido de la crisis mundial y que volvió a recuperarse en el 2010. En tal sentido, el ejercicio 2013 representa un año con un crecimiento real moderado de $5,8 \%$, muy cercano al promedio de crecimiento de la última década.

De igual forma, se observa que, si bien 2013 fue un buen año de ingresos provenientes de la explotación de materias primas, no fue precisamente el mejor, ya que la mayor cantidad de transferencias por dichos recursos se presentó en el 2007. Así, el promedio de ingresos por canon minero -que representa más del $50 \%$ de los ingresos totales por canon- entre 2004 y 2014 fue de S/. 3078 millones, y en 2013 fue de $\mathrm{S} / .3817$ millones, debido a la declinación de los precios de los metales a partir del 2011. Adicionalmente, el superávit fiscal en el ejercicio 2013 fue de 0,9\%, respetando la regla fiscal que exige que no sea mayor a $1 \%$ del PBI. Por estas consideraciones, 2013 representa un año típico de ingresos por transferencias, ideal para un análisis como el que se pretende realizar en este artículo.

b) Respecto de las unidades institucionales analizadas, nos limitamos a la de los gobiernos regionales, municipalidades provinciales y municipalidades distritales; se obvian los recursos que fueron a las mancomunidades ${ }^{6}$ y organismos públicos descentralizados (OPD) municipales. Asimismo, de la información recopilada,

6 Una mancomunidad, sea municipal o regional, se define como el acuerdo voluntario de dos o más circunscripciones territoriales, colindantes o no, que se unen para la prestación conjunta de servicios y la ejecución de obras, promoviendo el desarrollo local, la participación ciudadana y el mejoramiento de la calidad de los servicios a los ciudadanos. se eliminaron cuatro distritos, en vista de que no se tenía información de carácter social, a pesar de contar con información presupuestal para el 2013 por S/. 28,9 millones ${ }^{7}$. Respecto a las transacciones, para el caso de las cuentas del presupuesto de ingresos, el análisis se realiza por lo recaudado, es decir, en función de los recursos financieros captados $\mathrm{u}$ obtenidos durante el año fiscal respectivo.

\section{Selección de cuentas}

Las cuentas que han sido consideradas como transferencias han sido seleccionadas del presupuesto de ingresos y gastos. En el caso de las cuentas de ingresos, se efectuó siguiendo un orden de desagregación, que parte de la clasificación por rubros y luego por la clasificación genérica y subgenérica del presupuesto de ingresos, de la siguiente forma:

a) En un primer nivel de selección de las cuentas de ingresos presupuestarios se incluyen por rubro las transacciones siguientes:

- Transacciones provenientes de la fuente de donaciones y transferencias (DyT). Comprenden los fondos financieros no reembolsables recibidos por el gobierno, provenientes de agencias internacionales de desarrollo; gobiernos, instituciones y organismos internacionales; personas naturales o jurídicas domiciliadas o no en el país; así como de transferencias de otros niveles de gobierno, incluidas las transferencias provenientes de entidades públicas y privadas sin exigencia de contraprestación. Cabe indicar que, según el MEFP del FMI, las donaciones son transferencias no obligatorias recibidas de otros gobiernos o de organismos internacionales.

7 Estas fueron: municipalidad distrital de Samugari, en la provincia de La Mar, San Miguel, departamento de Ayacucho; municipalidad distrital de Cosme, en Churcampa, Huancavelica; municipalidad distrital de Yacus, en Yacus, Huanuco; y municipalidad distrital de Constitución, en Oxapampa, Pasco. 
- Transacciones provenientes de la fuente de recursos determinados (RD). Comprenden las contribuciones a fondos, como el Fondo de Compensación Municipal (FONCOMUN) y el FONCOR; el impuesto a los casinos y tragamonedas, que es un impuesto en coparticipación no recaudado ni administrado directamente por los gobiernos locales, sino por el Gobierno Nacional; y los conceptos de canon y sobrecanon $^{8}$, regalías ${ }^{9}$, renta de aduanas ${ }^{10}$ y otras participaciones.

Asimismo, se excluyen los recursos directamente recaudados por los gobiernos subnacionales (cuyos principales importes corresponden al impuesto predial, a la propiedad vehicular y alcabala) y los recursos por operaciones oficiales de crédito.

b) En un segundo nivel de selección, se substrae de la genérica de ingresos los recursos de endeudamiento $(E)$, salvo los relacionados con los fideicomisos regionales ${ }^{11}$ y los saldos de balance ( $\mathrm{SdB}$ ), por las razones siguientes:

- En el caso del endeudamiento, aunque dichos recursos son pequeños, dadas las reglas fiscales establecidas, suponen un crédito que amplía la restricción presupuestal en el ejercicio presente, pero

8 En términos doctrinarios, el canon es una compensación del Estado a los gobiernos regionales y locales de las zonas de explotación de recursos naturales respecto a la distribución de ingresos ya recaudados.

9 Es la contraprestación económica que los sujetos de la actividad minera pagan al Estado por la explotación de los recursos minerales metálicos y no metálicos, justificada en la necesidad de la Nación de recibir beneficios de sus propios recursos antes de que se agoten; de esta forma, se diferencia tanto del canon minero como del derecho de vigencia. Se entienden como sujetos de la actividad minera tanto a los titulares de las concesiones mineras como a los cesionarios que realizan las actividades de explotación;

10 La renta de aduanas es un recurso que se transfiere a las municipalidades provinciales y distritales de una determinada provincia y corresponde al $2 \%$ de las rentas recaudadas por cada una de las aduanas marítimas, aéreas, postales, fluviales, lacustres y terrestres ubicadas en la jurisdicción respectiva, por operaciones de importación.

11 Actualmente, solo existe un fideicomiso que involucra a la región de San Martín. que deberán ser devueltos en el futuro (equivalencia ricardiana); por ello, a efectos de no alterar la cuantificación neta de las transacciones en el ejercicio, se ha resuelto no considerarlas.

- En el caso de los saldos de balance, estos no se han considerado en vista de que dichos recursos financieros se obtienen del resultado de ejercicios anteriores, los cuales financian gastos en el ejercicio vigente. Los SdB han aumentado considerablemente en los últimos años, por lo que, al igual que el endeudamiento, no reflejan la distribución real de recursos del ejercicio y distorsionarían el análisis que se pretende realizar.

c) En un tercer nivel de selección se excluyen las donaciones y transferencias que provengan de fuentes del exterior, ya se trate de personas naturales, jurídicas, gobiernos, etc. Sin embargo, en el agrupamiento de DyT, en realidad la mayor parte de recursos de esta categoría es entre unidades institucionales internas, principalmente del Gobierno Nacional. Por esta razón, se incluirán muchas partidas de la categoría de donaciones y transferencias, en tanto se excluirán específicamente las que se hubieren recibido directamente de organismos internacionales y otros no residentes. Esto se sustenta en lo siguiente: si bien cuando se compilan las estadísticas para el sector de Gobierno General, las donaciones provenientes de otras unidades de gobierno se eliminan en la consolidación, de forma que solo aparezcan las donaciones provenientes de gobiernos extranjeros y organismos internacionales, el presente análisis proviene del Presupuesto de la República, y además la mayor parte corresponde a transferencias del Gobierno Nacional. Sin embargo, se encuentra posible que en las cuentas de DyT entre los gobiernos 
subnacionales (región o municipio provincial y distrital) pueda haber diferencias que deban consolidarse; por ejemplo, cuando dichos recursos transferidos provinieron inicialmente del Gobierno Nacional, y luego parte de estos se derivaron como una transferencia del gobierno regional a un municipio provincial o distrital. Sin embargo, del análisis presupuestal, como ya se mencionó, se observa que casi la totalidad de las transferencias evaluadas provino directamente del Gobierno Nacional, por lo que, si bien ello afecta las estadísticas del Gobierno General, no se afecta significativamente las estadísticas de los gobiernos subnacionales.

d) Se incluyen todos los intereses que son rentas de propiedad y los ingresos generados por la variación del tipo de cambio, que en el MEFB del FMl se denominan otros flujos económicos.

e) A los rubros anteriores extraídos del presupuesto de ingresos se suman los recursos ordinarios (RO) que provienen del presupuesto de gastos; se considera que dichos recursos, aunque muchas veces no son considerados en los análisis, también representan transferencias de nivelación. Los RO corresponden principalmente a los ingresos provenientes de la recaudación tributaria (impuestos nacionales) y otros conceptos, una vez son deducidas las sumas correspondientes a las comisiones de recaudación y servicios bancarios, los cuales no están vinculados a ninguna entidad y constituyen fondos disponibles de libre programación. Se toman en cuenta dichos gastos por categoría presupuestal y utilizando la información con base en el devengado.

Una verificación contable con el Estado de Programación y Ejecución de Ingresos y Gastos de la Cuenta General de la República, para verificar cuánto se pierde en la consolidación de cuentas en términos de transacciones entre distintos niveles de gobierno, determinó que para el caso de las municipalidades, la diferencia de cifras entre las transacciones evaluadas y los de la CGR fue menor en $0,03 \%$ sobre el total ejecutado del Estado de Cuenta, y en el caso de los gobiernos regionales hubo una diferencia ligeramente mayor de $1,2 \%$.

\section{Reclasificación de cuentas}

Las transacciones específicas consideradas son las que se presentan en la tabla 2 simplificada ${ }^{12}$, la cual muestra la fuente oficial de recursos tal como se presenta en el portal de Transparencia Económica del MEF de los tres rubros de donde se extrajo la información, y un primer reagrupamiento de las cuentas en quince conceptos, en función de la importancia de dichos recursos para distinguir la orientación de la política fiscal descentralista y sus restricciones.

Para los gobiernos regionales, las transferencias totales ascendieron a S/. 21.205 millones, que en su mayoría resultan ser transferencias de recursos ordinarios. Para los gobiernos locales, las transferencias totales ascendieron a S/. 17.531 millones, de los cuales correspondieron a los municipios provinciales S/. 7.260 millones y a los municipios distritales un total de S/. 10.271 millones. En este caso, la mayor parte de transferencias provino de la fuente de recursos determinados.

En un segundo nivel de agrupamiento, los quince conceptos se agregan nuevamente de acuerdo con su origen y la finalidad que persigue esta investigación de descubrir patrones de equidad en la distribución de los recursos de las transferencias fiscales, tal como se aprecia en la tabla 3.

Así, dicha reclasificación se efectúa en tres grupos de la siguiente forma:

12 Las cuentas exactas que han sido reclasificadas pueden ser consultadas en el siguiente enlace: https://www.dropbox.com/ sh/1jv52htlfpunygl/AACjhoEhe6Yqb6mu9j_3nhS6a?dl=0 
Tabla 2.

Reagrupamiento de cuentas fiscales en el Perú

\begin{tabular}{|c|c|c|c|}
\hline \multirow{2}{*}{$\begin{array}{l}\text { Fuente oficial de } \\
\text { financiamiento }\end{array}$} & \multicolumn{2}{|c|}{ Cuentas por rubro (genérica /subgenérica) } & \multirow[b]{2}{*}{ Primer reagrupamiento de cuentas para el análisis } \\
\hline & $\begin{array}{c}\text { Gobiernos } \\
\text { regionales }\end{array}$ & Gobiernos locales & \\
\hline \multirow{3}{*}{$\begin{array}{l}\text { Donaciones y } \\
\text { transferencias }\end{array}$} & \multirow{3}{*}{23} & \multirow{3}{*}{19} & Apoyo en gestión a gobiernos \\
\hline & & & Transferencias entre gobiernos e instituciones \\
\hline & & & Transferencias a fondos o programas específicos \\
\hline \multirow{15}{*}{$\begin{array}{c}\text { Recursos } \\
\text { determinados }\end{array}$} & \multirow{15}{*}{68} & \multirow{15}{*}{96} & Apoyo en gestión a gobiernos \\
\hline & & & Canon forestal \\
\hline & & & Canon gasífero \\
\hline & & & Canon hidroenergético \\
\hline & & & Canon minero \\
\hline & & & Canon pesquero \\
\hline & & & Canon petrolero \\
\hline & & & Focam \\
\hline & & & FONCOMÚN \\
\hline & & & Impuesto a los juegos de casinos y tragamonedas \\
\hline & & & Participaciones \\
\hline & & & Regalías mineras \\
\hline & & & Rentas de aduana \\
\hline & & & Transferencias entre gobiernos e instituciones \\
\hline & & & Transferencias a fondos o programas específicos \\
\hline \multirow{3}{*}{ Recursos ordinarios } & \multirow{3}{*}{42} & \multirow{3}{*}{36} & Apoyo en gestión a gobiernos \\
\hline & & & Transferencias entre gobiernos e instituciones \\
\hline & & & Transferencias a fondos o programas específicos \\
\hline Total de cuentas & 133 & 151 & \\
\hline
\end{tabular}

Fuente: elaboración del autor.

Tabla 3.

Fuente fiscal agregada para el análisis en el Perú

\begin{tabular}{|c|c|}
\hline Primer reagrupamiento de cuentas para el análisis & Segundo nivel de agrupamiento \\
\hline Apoyo en gestión a gobiernos subnacionales & \multirow{3}{*}{$\begin{array}{l}\text { Transferencias discrecionales mayormente } \\
\text { condicionadas }\end{array}$} \\
\hline Transferencias a fondos o programas específicos & \\
\hline Transferencias entre gobiernos e instituciones & \\
\hline Canon forestal & \multirow{9}{*}{$\begin{array}{l}\text { Transferencias por explotación económica de recursos } \\
\text { naturales }\end{array}$} \\
\hline Canon gasífero & \\
\hline Canon hidroenergético & \\
\hline Canon minero & \\
\hline Canon pesquero & \\
\hline Canon petrolero & \\
\hline Focam & \\
\hline Regalías mineras & \\
\hline Participaciones & \\
\hline Impuestos municipales (casinos y tragamonedas) & \multirow{3}{*}{ Transferencias de impuestos en coparticipación } \\
\hline FONCOMÚN & \\
\hline Rentas de aduana & \\
\hline
\end{tabular}

Fuente: elaboración del autor. 
a) Las transferencias discrecionales mayormente condicionadas, que resultan discrecionales porque son a voluntad del Gobierno Nacional y normalmente están condicionadas para los gobiernos subnacionales. En esta categoría se incluye todos los recursos ordinarios, que son destinados a los programas sociales y a fondos específicos como el Instituto Nacional de Defensa Civil (INDECI), el Fondo de Promoción a la Inversión Pública Regional y Local (FONIPREL), los fideicomisos regionales, etc.

b) Las transferencias por la explotación económica de recursos naturales, que incluyen todos los ingresos tributarios $y$ no tributarios, como el canon, las regalías y otras participaciones.

c) Las transferencias de impuestos en coparticipación, que incluyen los impuestos a las embarcaciones de recreo, el de promoción municipal, rodaje, etc., que forman parte del FONCOMUN, las rentas de aduana y el impuesto a los juegos de casinos y tragamonedas.

\section{ANÁLISIS DE LA HETEROGENEIDAD HORIZONTAL DE LOS GOBIERNOS SUBNACIONALES}

Como se mencionó, analizar la heterogeneidad fiscal de los gobiernos subnacionales implica determinar si los recursos son asignados siguiendo criterios de equidad, asumiendo que todos, como ciudadanos, tenemos el mismo derecho de recibir los beneficios del crecimiento económico.

Por otra parte, sin embargo, la eficiencia económica exige reconocer la provisión adecuada de bienes públicos en relación con la demanda de la comunidad, lo cual se logra a partir de la premisa microeconómica de que la suma de las tasas marginales de sustitución entre los bienes debe ser igual a sus precios relativos o, en términos de equilibrio general, a su tasa de transformación; pero ello está sujeto además a fuertes externalidades intra- e interjurisdiccionales que deben ser tomadas en cuenta.

Este apartado se centrará únicamente en analizar las transferencias desde una perspectiva de equidad, subrayando en cada parte del análisis las razones de eficiencia que están detrás de cada posible situación de distribución de los recursos fiscales. Para ello, partiremos de definir las fuentes de información y la metodología seguida, para luego presentar los principales hallazgos del análisis.

\section{Consideraciones metodológicas para el análisis de las transferencias}

Para el caso de la medición de la heterogeneidad horizontal en la distribución de las transferencias fiscales, se ha hecho uso de índices o indicadores de desigualdad. Un índice de desigualdad puede definirse como una función $I: \mathfrak{I} \rightarrow \mathfrak{R}$, donde $V: \mathfrak{I} \rightarrow \mathfrak{R}$ es el espacio de todas las funciones de distribución posibles de la variable medida, que asigna un número real a cada posible distribución de la variable. En el escenario discreto, es el conjunto de todos los pares $(N, Y)$ que describen una cierta sociedad con un tamaño de población $N$ y una distribución sobre una variable $Y$, que normalmente se trata de ingresos. Para nuestra investigación, el par ordenado estará compuesto por cada unidad gubernamental subnacional, mientras la variable medida serán los ingresos por transferencias recibidos por cada unidad.

Para que sea consistente, todo indicador de desigualdad debe cumplir con ciertas propiedades deseables, como son la descomponibilidad aditiva, simetría, réplica de poblaciones, transferencia de Dalton, continuidad y diferenciabilidad, independencia de la escala y normalización; propiedades que pueden ser examinadas en Goerlich y Villar (2009). Existe un gran número de índices de desigualdad que cumplen con dichas propiedades; sin embargo, en este artículo se hará uso de cinco de ellos, que cumplen con dichas propiedades y 
cuya medición resulta más adecuada a los datos obtenidos para este análisis.

Así, dentro de los cinco índices escogidos, cuatro tienen carácter cuantitativo y uno es de carácter gráfico (curva de Lorenz). De los cuantitativos, tres de ellos son medidas positivas de la desigualdad que se basan tan solo en la distribución de la variable medida (en el presente caso, las transferencias fiscales): el coeficiente de variación, el índice de Gini y el índice de Theil normalizado. El cuarto es el índice de Atkinson, que se circunscribe a las medidas normativas, puesto que se basa en una consideración de la función de bienestar social subyacente, es decir, en un juicio de valor acerca de la naturaleza de la desigualdad, pero en este caso a partir de la propia información proporcionada por los datos.

En tal sentido, un aspecto crucial en el análisis de la desigualdad a través de este último indicador es la aproximación de la desigualdad a la medición del bienestar. Esta relación puede abordarse desde las denominadas funciones de evaluación social (V). Una función de este tipo se define como una aplicación del espacio de distribuciones de la variable medida en los números reales, $V: \mathfrak{I} \rightarrow \mathfrak{R}$ , que verifica las propiedades de homogeneidad y diferenciabilidad; por tanto, corresponde a un caso particular de las funciones de bienestar social ${ }^{13}$.

En otras palabras, estas funciones permiten expresar la valoración social de un vector de la variable medida (como puede ser la renta) relacionada con el bienestar como una suma ponderada de ellas. Para que dichas funciones sean una buena aproximación, deben cumplir con una condición llamada de $S$-consistencia o, lo que es lo mismo, de consistencia en el sentido de Sen. Dicha condición establece que un sistema de coeficientes de ponderación $\left(\alpha_{i}(y)\right)_{i \in N}$ genera una función de evaluación social $V(y)$ S-consistente con el índice de desigualdad $I(y)$, donde $y$ representa el espacio de distribuciones de renta; pero en la presente

13 De hecho, en este punto se obvia la discusión existente sobre la desigualdad en renta versus la desigualdad en bienestar y de la correspondencia que existe entre los índices de desigualdad y las funciones de bienestar social. investigación se refiere a las transferencias fiscales si y solo si para toda distribución $y$, puede expresarse la función $V(y)$ como:

$$
\begin{aligned}
V(y)= & \sum_{i=1}^{n} \alpha_{i} V(y)=n \xi=Y(1-I(y) \\
& \text { Donde } \alpha_{i}(y)=\frac{1 \partial V}{\varphi \partial y_{i}}, y \varphi \text { es el grado de }
\end{aligned}
$$
homogeneidad de $V(y)^{14}$.

Una ventaja de esta función es que cuando existen diferencias económicas que no se limitan a diferencias de renta (por ejemplo, diferencias en el tamaño de la unidad familiar, de sus necesidades o de sus dotaciones de bienes de consumo duradero), estos coeficientes de ponderación pueden ser factorizados en la forma $\alpha i(y)=\Upsilon_{i} a_{i}(y)$, donde $r_{i}$ es la ponderación del individuo $i$ por causas no vinculadas a la renta.

A pesar de ello, como bien señalan Goerlich y Villar (2009), la adopción de esta formulación supone también algunas restricciones. En particular se está excluyendo el uso de funciones de valoración de tipo leximin ${ }^{15}$, que vinculan la valoración social exclusivamente al individuo que está peor situado en la distribución. También se está adoptando indirectamente una aproximación relativa a la medición de la desigualdad, dada la homogeneidad de los coeficientes de ponderación.

En el presente caso, para aproximarse a la construcción de dicha función de evaluación S-consistente, la ponderaci ón se efectúa a partir de variables sociales seleccionadas (estas se detallan más adelante), utilizando dos técnicas estadísticas: la de componentes principales y la de escalamiento óptimo.

14 Este resultado se deriva directamente del teorema de Euler, que establece que una función homogénea y diferenciable puede expresarse como una suma ponderada de sus variables, donde los coeficientes de ponderación son proporcionales a sus derivadas parciales, con un grado de proporcionalidad dado por la inversa del grado de homogeneidad de la función.

15 Como principio de asignación el criterio leximin definido por Sen, exige tomar en cuenta la situación de los menos favorecidos, luego la de los segundos menos favorecidos, la de los terceros menos favorecidos y así sucesivamente; la prioridad general es mejorar la situación de los menos favorecidos. 
El análisis de componentes principales (ACP) es una técnica del análisis factorial ${ }^{16}$ consistente en la reducción de datos sobre variables numéricas; utiliza la correlación entre las variables originales para construir combinaciones lineales comunes que permitan explicar la mayor parte posible de la información recogida en dichas variables. En este sentido, el ACP permite obtener un nuevo conjunto de variables (las componentes principales) que gozan de la ventaja de estar incorrelacionadas entre sí, al tiempo que usan la varianza como medida de la cantidad de información que llevan incorporadas. Sin entrar en los detalles de la técnica estadística, puede formularse el modelo de la siguiente forma:

$Z_{1}=\mu_{11} X_{1}+\mu_{12} X_{2}+\ldots+\mu_{1 p} X_{p}$ $Z_{2}=\mu_{21} X_{1}+\mu_{22} X_{2}+\ldots+\mu_{2 p} X_{p}$ :

$Z_{n}=\mu_{n 1} X_{1}+\mu_{n 2} X_{2}+\ldots+\mu_{n p} X_{p}$

Donde las $X_{i}$ son las variables numéricas originales del modelo, $Z_{i}$ son los componentes principales extraídos y $U_{i j}$ son los coeficientes que hay que aplicar a las variables originales para obtener las componentes principales.

En el presente caso se han utilizado en primer término los componentes principales para encontrar un único índice de tenencia de bienes a partir de información extraída de la Encuesta Nacional de Hogares y Vivienda (ENAHO), por el método de las componentes principales y rotando los factores por el método Varimax. Dicho índice se incorporó luego como un argumento adicional para encontrar la función de evaluación social, que determine la distribución de las transferencias fiscales bajo parámetros de equidad social.

16 El análisis factorial tiene sus orígenes en los trabajos iniciados por Charles Spearman en 1904, donde trataba de analizar la causa de que las puntuaciones obtenidas por un grupo de alumnos en distintas materias presentaran altas correlaciones. Los estudios de Spearman pusieron de manifiesto la existencia de un factor común en todas las calificaciones, que da una medida de la inteligencia de los alumnos y que explicaría las altas correlaciones existentes, y de otro factor, específico de cada alumno, que sería el responsable de la parte residual de las calificaciones.
Posteriormente, para la construcción de la función de evaluación social mencionada a partir de muchas variables de condición social, incluido el índice de tenencia de bienes, se utilizó la metodología de escalamiento óptimo, que es también una técnica de reducción de datos, pero que, a diferencia del análisis factorial, permite trabajar con variables cuya escala no es numérica, sino binomial, nominal múltiple u ordinal. Dicho procedimiento matemático se basa en la asignación de cuantificaciones numéricas a las categorías de cada variable no numérica (normalmente frecuencias), para así obtener soluciones matemáticas a partir de dichas cuantificaciones.

Existen varias técnicas dentro de la metodología del escalamiento óptimo: la técnica de análisis de correspondencias, que se circunscribe a cuando todas las variables son nominales; la técnica de escalamiento multidimensional, que permite aflorar criterios subyacentes a partir de la asociación de objetos; el análisis canónico, que se aplica cuando las variables dependientes e independientes son grupos de variables; y la técnica de componentes principales no lineales o categóricos, cuyo objetivo es identificar dimensiones o variables latentes (componentes) que expliquen las relaciones entre las variables originales observadas, cuya escala puede ser nominal, ordinal o numérica, o bien, una combinación de estas, por lo cual se trata de relaciones no lineales.

En esta investigación se hace uso de la última de las técnicas mencionadas, en la medida en que lo importante es la existencia de asociación o covarianza entre las variables. Esta técnica utiliza el algoritmo de mínimos cuadrados alternantes, que, en primer lugar, cuantifica las categorías de las variables, de modo que se pueda maximizar la correlación entre las variables; luego utiliza estas cuantificaciones para estimar los parámetros del análisis lineal de componentes principales, proceso que se realiza en forma iterativa alternada.

El análisis de la desigualdad de las transferencias fiscales se efectúa para la totalidad de transferencias en su conjunto y luego para cada subgrupo de la reclasificación efectuada, como se explicó anteriormente. Asimismo, para mejorar 
la comparabilidad de los datos, a cada subgrupo reclasificado se aplica el análisis por nivel de gobierno subnacional (regional, municipal provincial y municipal distrital), regiones geográficas en el Perú (costa, sierra, selva y Lima Metropolitana) y espacio geográfico (rural y urbano) ${ }^{17}$. Los dos últimos aspectos atienden a que en el Perú existen marcadas diferencias en cuanto a variables sociales por región y espacio geográfico - a diferencia de otros países-. que, si no se consideran, sesgan el análisis.

En lo que se refiere a la fuente de datos de variables sociales utilizadas en el análisis, cabe indicar que todas provienen de las diversas estadísticas recopiladas por el Instituto Nacional de Estadística e Informática (INEI), en el último censo del 2007; de la Encuesta Nacional de Hogares (ENAHO), con la metodología actualizada 2013; y del Directorio Nacional de Municipalidades y Centros Poblados (RENAMU), que se encuentran en su repositorio de microdatos. El detalle de las variables usadas en el análisis de la función de evaluación social se presentan en la tabla 4.

Tabla 4.

Variables utilizadas para hallar la función de evaluación social

- Factor de tenencia de bienes. Se obtuvo a partir del análisis factorial, tomando en consideración las variables siguientes provenientes de la ENAHO 2013:

- No tenencia de teléfono fijo en el hogar.

- No tenencia de teléfono celular en el hogar.

- No tenencia de televisión a color en el hogar.

- No tenencia de computadora personal en el hogar.

- No tenencia de licuadora en el hogar.

- No tenencia de cocina de gas en el hogar.

- No tenencia de refrigeradora en el hogar.

- No tenencia de lavadora en el hogar.

- Indicador de porcentaje de población rural. Construido a partir de los porcentajes de población rural y urbana en cada distrito. Si la población urbana es mayor (igual o superior al $50 \%$ ), se considera urbano; de lo contrario, se considera rural. Fuente: INEI, Censos Nacionales 2007: XI de Población y VI de Vivienda.

17 Puesto que el único índice que cumple con la propiedad de descomponibilidad aditiva para subgrupos de población es el de Theil, y no el de Gini o Atkinson, en este caso debe aclararse que en la presente investigación no se pretende establecer la atribución de dicha desigualdad a un tipo de transferencias en particular, sino tan solo evidenciar la desigualdad manifiesta en cada componente.
- Porcentaje de población no PEA (menores de 14 y mayores de 65 años). Fuente de información: INEI, Proyecciones para el año 2013 según Censo XI de Población y VI de Vivienda 2007.

- Indicador de incidencia ponderada de la pobreza monetaria (IPM). Para la construcción de este indicador se utilizó el indicador de pobreza monetaria que publica el INEI en sus dos niveles: pobreza y pobreza extrema, de cuya diferencia se obtienen los pobres no extremos. Además, se consideró otorgarle una mayor ponderación a la situación de pobreza extrema de la población, versus la situación de pobreza no extrema, y aunque ambas están correlacionadas geográficamente, permite afinar el criterio de equidad que se busca en la distribución de las transferencias. En tal sentido, se acordó otorgarle una ponderación de $70 \%$ para la pobreza extrema y de $30 \%$ para la pobreza no extrema. Por tanto, el indicador que hemos denominado $\mathrm{IPM}=0,7 \times \%$ de incidencia en pobreza extrema $+0,3$ $\times \%$ de incidencia en pobreza no extrema. Fuente de la información: INEI, Sistema de Información Regional para la Toma de Decisiones, Censo de Población y Vivienda 2007. Calculados por el INEI para 2009.

- Porcentaje de población con al menos una necesidad básica insatisfecha (NBI). Fuente: ENAHO 2013. Las variables que se toman en cuenta para el NBI son:

- Vivienda inadecuada (NBI 1).

- Vivienda con hacinamiento (NBI 2).

- Hogares con vivienda sin servicios higiénicos (NBI 3).

- Hogares con niños que no asisten a la escuela (NBI 4). - Hogares con alta dependencia económica (NBI 5).

- Región geográfica según data de dominio geográfico (costa, sierra, selva, Lima Metropolitana) y por departamento cuando no hubiere sido posible la primera. Fuente: INEI.

- Tipo de municipio (provincial o distrital). Fuente: MEF, INEI (RENAMU).

- Clasificación por densidad poblacional de los centros poblados. Fuente: INEI.

- Hogares con abastecimiento de agua por red pública, dentro de la vivienda y edificio. Fuente: ENAHO 2013.

- Calidad bacteriológica del agua es segura. Fuente: ENAHO 2013.

- Hogares con electricidad como tipo de alumbrado en el hogar. Fuente: ENAHO 2013.

- Mortalidad infantil y de mujer (niños < 5 años y mujeres en edad fértil) Fuente: Censo 2007.

- Nivel de analfabetismo en mayores de 15 años. Fuente: ENAHO 2013

- Personas que no tienen DNI a partir de 18 años. Fuente: ENAHO 2013.

- Personas que padecen enfermedad o malestar crónico. Fuente: ENAHO 2013.

Fuente: elaboración del autor.

La recopilación de la información se ha realizado utilizando primordialmente la hoja de cálculo de MS Excel, pero en parte también por descarga 
directa en SPSS (programa estadístico para las ciencias sociales), como en el caso de las encuestas de ENAHO. Para los cálculos y las estimaciones que aparecen en las tablas y gráficos también se hizo uso de ambos programas ${ }^{18}$.

\section{Análisis de la heterogeneidad de las transferencias fiscales}

De acuerdo con la metodología establecida en la subsección anterior, el primer análisis es presentar el total de recursos considerados a partir de la clasificación oficial hecha por fuente de recaudación de los gobiernos subnacionales. En la tabla 5 se puede apreciar que el $73,1 \%$ de los recursos de transferencias recibidas por los gobiernos locales procede de los recursos determinados (RD), seguido de los recursos ordinarios, con el $21,7 \%$. Por el contrario, en el caso de los gobiernos regionales, el 83\% proviene principalmente de recursos ordinarios, y solo el $12,3 \%$ proviene de recursos determinados.

Tabla 5.

Recursos transferidos en el Perú según fuente oficial de financiamiento, 2013

\begin{tabular}{|c|c|c|c|c|}
\hline \multirow{2}{*}{$\begin{array}{c}\text { Fuente de } \\
\text { financiamiento }\end{array}$} & \multicolumn{2}{|c|}{ Gobiernos locales } & \multicolumn{2}{c|}{$\begin{array}{c}\text { Gobiernos } \\
\text { regionales }\end{array}$} \\
\cline { 2 - 5 } & $\begin{array}{c}\text { Importe } \\
\text { (millones } \\
\text { de S/.) }\end{array}$ & $\%$ & $\begin{array}{c}\text { Importe } \\
\text { (millones } \\
\text { de S/.) }\end{array}$ & $\%$ \\
\hline $\begin{array}{c}\text { Donaciones y } \\
\text { transferencias } \\
\text { (DyT) }\end{array}$ & 918,40 & $5,2 \%$ & 992,41 & $4,7 \%$ \\
\hline $\begin{array}{c}\text { Recursos } \\
\text { determinados } \\
\text { (RD) }\end{array}$ & $12.810,75$ & $73,1 \%$ & $2.618,30$ & $12,3 \%$ \\
\hline $\begin{array}{c}\text { Recursos } \\
\text { ordinarios (RO) }\end{array}$ & $3.805,19$ & $21,7 \%$ & $17.594,66$ & $83,0 \%$ \\
\hline Total & $17.534,34$ & $100,0 \%$ & $21.205,37$ & $100,0 \%$ \\
\hline
\end{tabular}

Fuente: elaboración del autor a partir de MEF, Portal de Transparencia.

18 La data y sintaxis en SPSS de las técnicas estadísticas que se describen en la metodología también se pueden encontrar en el siguiente enlace: https://www.dropbox.com/ sh/1jv52htlfpunygl/AACjhoEhe6Yqb6mu9j_3nhS6a?dl=0
En cuanto a la distribución de los recursos per cápita a nivel de distritos, en el gráfico 5 se observa una aparente distribución desigual de los recursos: el importe del gobierno local que menos recibe es de S/. 29,3 (habitantes del distrito de Surco, en Lima) y el que más recibe es de S/. 15.830,6 (habitantes del distrito de llabaya, en Tacna). En el caso de las provincias, la de Chiclayo, en Lambayeque, es la que recibe menos recursos: S/. 156,71 por persona; y la de Jorge BasadreLocumba, en Tacna, es la que recibe los mayores recursos, con un importe de S/. 10.550,74. En el caso de los gobiernos regionales, la distribución de las transferencias per cápita también presenta una distribución aparentemente desigual, con un mínimo de S/. 6,1 y un máximo de S/. 2223,3.

Gráfico 5

Curva de Lorenz de transferencias totales en el Perú, 2013

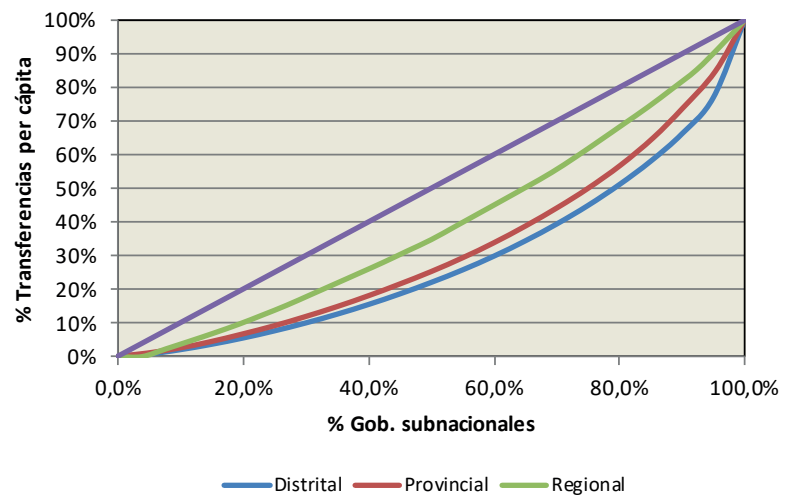

Fuente: elaboración del autor.

Para evaluar la magnitud de esta desigualdad, se utilizarán algunos de los índices de desigualdad más comúnmente usados en la literatura. En la tabla 6 puede verse que, en todos los casos, los índices corroboran la existencia de desigualdad en la distribución de los recursos per cápita, aunque de bajo nivel; la mayor desigualdad existe entre los municipios distritales, y en último término, entre los gobiernos regionales.

Si se desagrega a nivel de municipios distritales entre rurales y urbanos, puede observarse en el gráfico 6 que existe una ligera mayor inequidad en el grupo de municipios urbanos. 
Tabla 6.

Índices de desigualdad de transferencias totales 2013 en el Perú*

\begin{tabular}{|c|c|c|c|}
\hline \multirow{2}{*}{ Índices } & \multicolumn{3}{|c|}{$\begin{array}{c}\text { Por nivel de gobierno } \\
\text { subnacional }\end{array}$} \\
\cline { 2 - 4 } & Distrital & Provincial & Regional \\
\hline Coeficiente de variación & 1,0756 & 0,8124 & 0,4108 \\
\hline Índice de Gini & 0,4298 & 0,3631 & 0,2167 \\
\hline Índice de Theil Normalizado & 0,0474 & 0,0443 & 0,0285 \\
\hline índice de Atkinson** & 0,3904 & 0,2846 & 0,5563 \\
\hline $\begin{array}{c}\text { Total de gobiernos } \\
\text { evaluados*** }\end{array}$ & 1.642 & 192 & 26 \\
\hline
\end{tabular}

*Las transferencias totales per cápita se utilizan como unidad de análisis. ${ }^{* *}$ Con parámetro de aversión a la desigualdad de 1,$5 ;{ }^{* * *} \mathrm{El}$ total de gobiernos subnacionales evaluados corresponde a aquellos de los que se tenía total información. Fuente: elaboración del autor a partir de MEF e INEI.

Por último, puede dividirse el grupo de municipios distritales entre las regiones geográficas tradicionales (costa, sierra, selva y Lima Metropolitana) y por categoría rural-urbano. En el gráfico 7 se puede observar que la desigualdad en la transferencia de recursos fiscales es ligeramente más pronunciada en la categoría de municipios urbanos que de municipios rurales tanto en la sierra como en la selva, pero que es muy similar en la costa.
Gráfico 6

Curva de Lorenz de transferencia totales en el Perú, 2013, gobiernos locales

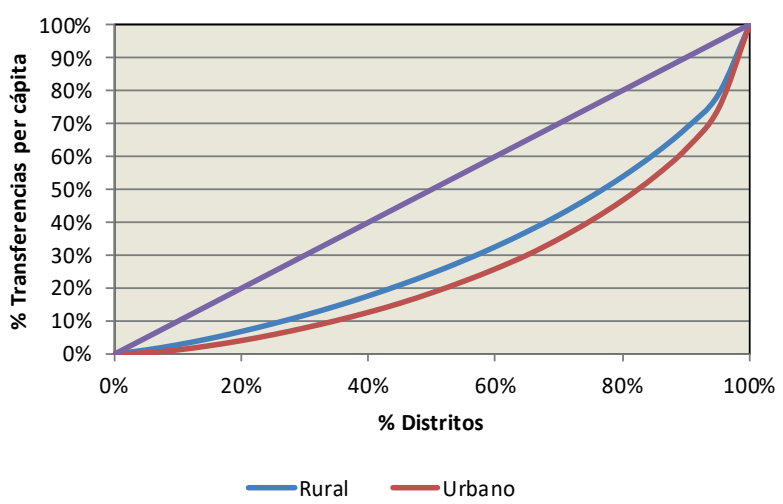

Fuente: elaboración propia.

Los índices de desigualdad para cada una de las regiones corroboran lo observado gráficamente en la curva de Lorenz. Como referencia, se puede mencionar que el índice de Gini nacional de la distribución de ingresos de la población, calculado a partir de la ENAHO, arrojó una desigualdad de 0,44 para 2013, el cual, como se muestra en la tabla 7, es superado ligeramente por la categoría de sierra urbana y ampliamente por la selva urbana y Lima Metropolitana.

Tabla 7.

Índices de desigualdad de transferencias totales en municipios distritales del Perú, 2013*

\begin{tabular}{|c|c|c|c|c|c|c|c|}
\hline \multirow{2}{*}{ Índices } & \multicolumn{9}{c|}{ Por región geográfica y categoría de urbanización } \\
\cline { 2 - 9 } & \multicolumn{2}{|c|}{ Costa } & \multicolumn{2}{c|}{ Sierra } & \multicolumn{2}{c|}{ Selva } & Lima Metropolitana \\
\cline { 2 - 8 } & Urbana & Rural & Urbana & Rural & Urbana & Rural & Urbana \\
\hline Coeficiente de variación & 1,1253 & 0,9705 & 1,2542 & 0,7824 & 1,7192 & 1,2167 & 1,1900 \\
\hline Índice de Gini & 0,4427 & 0,4007 & 0,4599 & 0,3577 & 0,5373 & 0,4332 & 0,5006 \\
\hline Índice de Theil normalizado & 0,0663 & 0,0587 & 0,0741 & 0,0351 & 0,1461 & 0,0779 & 0,1220 \\
\hline Índice de Atkinson** & 0,3987 & 0,3015 & 0,3910 & 0,2615 & 0,4765 & 0,3363 & 0,4485 \\
\hline $\begin{array}{c}\text { Total de gobiernos } \\
\text { evaluados*** }\end{array}$ & 278 & 188 & 281 & 624 & 75 & 154 & 42 \\
\hline
\end{tabular}

*Las transferencias totales per cápita se utilizan como unidad de análisis. * Con parámetro de aversión a la desigualdad de 1,5;

${ }^{* * *}$ El total de gobiernos subnacionales evaluados corresponde a aquellos de los que se tenía total información.

Fuente: elaboración del autor a partir de MEF e INEI. 
Transferencias distritales totales por zonas geográficas en el Perú, 2013

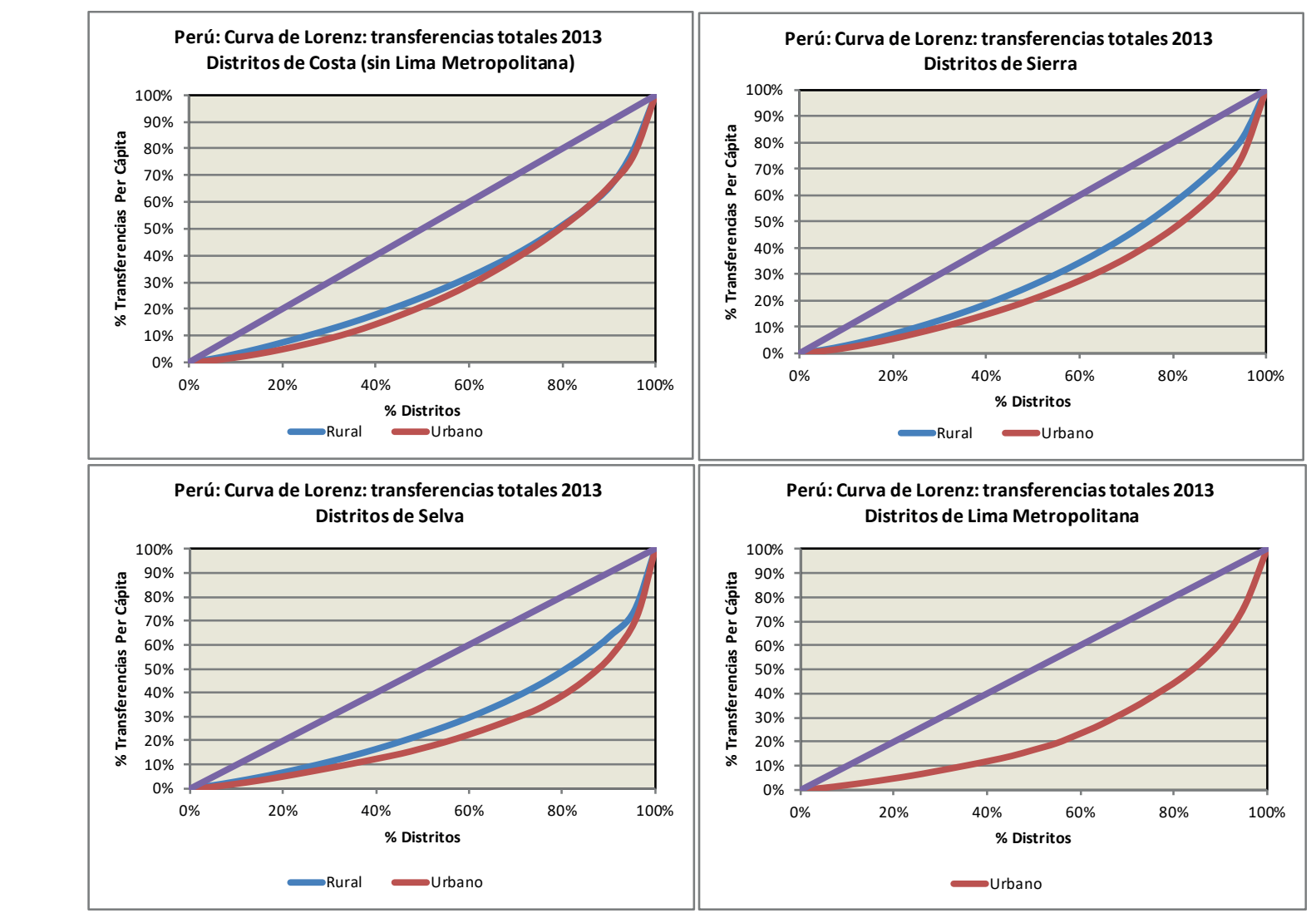

Fuente: elaboración del autor.

Pasando a analizar la información desde la clasificación planteada en este trabajo para las transferencias, más allá de la clasificación hecha oficialmente, se puede observar en la tabla 8 que, en el caso de los gobiernos locales, casi el $25,6 \%$ de los recursos provino del FONCOMúN, repartido casi homogéneamente entre los municipios provinciales y distritales, y el $16,6 \%$ del canon minero, aunque en este caso, tres cuartas partes les correspondieron a los municipios distritales.

En el tercer lugar de importancia, con 15,3\%, se encuentran los recursos de transferencias a fondos o programas específicos, donde, contrariamente a lo señalado para el canon minero, son esta vez los municipios provinciales los que reciben el $72,3 \%$ del total. Finalmente, del canon gasífero reciben el $10,45 \%$ de los recursos, donde el $85 \%$ les correspondió a los municipios distritales.

En lo que respecta a los gobiernos regionales, en la tabla 9 se muestra que el $75,6 \%$ de los recursos provino de las transferencias a fondos 0 programas específicos, en tanto el 7,4\% procedió de transferencias entre gobiernos e instituciones mayoritariamente del Gobierno Nacional.

A partir de aquí puede realizarse el análisis de distribución de los recursos transferidos para cada uno de sus componentes, según la nueva reclasificación y agrupamiento. Así, en la tabla 10 se observa que los mayores ingresos por transferencias para los gobiernos subnacionales en el 2013 fueron recursos a discreción del Gobierno Central, pero mayormente condicionadas a los gobiernos 
Tabla 8.

Recursos transferidos según reclasificación de fuente de financiamiento en el Perú, gobiernos locales, 2013*

\begin{tabular}{|c|c|c|c|c|}
\hline $\begin{array}{l}\text { Fuente oficial de } \\
\text { financiamiento }\end{array}$ & Fuente reclasificada para el análisis & Provinciales & Distritales & Total \\
\hline \multirow{4}{*}{$\begin{array}{l}\text { Donaciones y } \\
\text { transferencias }\end{array}$} & Apoyo en gestión a gobiernos & 0,00 & 0,00 & 0,00 \\
\hline & Transferencias entre gobiernos e instituciones & 6,06 & 3,82 & 4,74 \\
\hline & Transferencias a fondos o programas específicos & 0,94 & 0,18 & 0,49 \\
\hline & Subtotal & 7,00 & 3,99 & 5,24 \\
\hline \multirow{16}{*}{$\begin{array}{c}\text { Recursos } \\
\text { determinados }\end{array}$} & Apoyo en gestión a gobiernos & 5,27 & 6,69 & 6,10 \\
\hline & Canon forestal & 0,00 & 0,00 & 0,00 \\
\hline & Canon gasífero & 3,84 & 15,12 & 10,45 \\
\hline & Canon hidroenergético & 0,35 & 1,30 & 0,91 \\
\hline & Canon minero & 9,90 & 21,41 & 16,64 \\
\hline & Canon pesquero & 0,41 & 0,66 & 0,56 \\
\hline & Canon petrolero & 4,60 & 4,57 & 4,58 \\
\hline & Focam & 2,21 & 1,57 & 1,83 \\
\hline & FONCOMÚN & 24,01 & 26,75 & 25,62 \\
\hline & Impuestos municipales (casinos y tragamonedas) & 1,49 & 0,50 & 0,91 \\
\hline & Participaciones & 0,11 & 0,00 & 0,05 \\
\hline & Regalías mineras & 1,46 & 2,98 & 2,35 \\
\hline & Rentas de aduana & 0,80 & 1,64 & 1,29 \\
\hline & Transferencias entre gobiernos e instituciones & 0,00 & 0,00 & 0,00 \\
\hline & Transferencias a fondos o programas específicos & 2,48 & 1,27 & 1,77 \\
\hline & Subtotal & 56,92 & 84,46 & 73,06 \\
\hline \multirow{4}{*}{ Recursos ordinarios } & Apoyo en gestión a gobiernos & 0,00 & 0,00 & 0,00 \\
\hline & Transferencias entre gobiernos e instituciones & 9,46 & 4,33 & 6,45 \\
\hline & Transferencias a fondos o programas específicos & 26,62 & 7,22 & 15,25 \\
\hline & Subtotal & 36,08 & 11,55 & 21,70 \\
\hline \multicolumn{2}{|r|}{ Total general** } & $7.260,33$ & $10.271,54$ & $17.531,87$ \\
\hline
\end{tabular}

*Incluye 1838 gobierno locales. ${ }^{* *}$ En millones de S/.

Fuente: elaboración del autor a partir de datos del MEF, Portal de Transparencia.

subnacionales, con el $64,14 \%$, que en su mayor parte fueron para gasto corriente. Se destacan los recursos asignados a los gobiernos regionales, en los que representó el $88,39 \%$ de sus transferencias recibidas totales, la mayor parte a transferencias para fondos o programas específicos. A su vez, los recursos recibidos por la explotación económica de recursos naturales alcanzaron el $22,75 \%$ y fueron recibidos en un $55 \%$ por los municipios distritales, para los cuales representó el $41 \%$ de sus recursos transferidos totales. 
Tabla 9.

Recursos transferidos según reclasificación de fuente de financiamiento en el Perú, gobiernos regionales, 2013*

\begin{tabular}{|c|c|c|}
\hline Fuente oficial de financiamiento & Fuente reclasificada para el análisis & $\%$ \\
\hline \multirow{4}{*}{ Donaciones y transferencias } & Apoyo en gestión a gobiernos subnacionales & 0,01 \\
\hline & Transferencias a fondos o programas específicos & 3,37 \\
\hline & Transferencias entre gobiernos e instituciones & 1,31 \\
\hline & Subtotal & 4,68 \\
\hline \multirow{14}{*}{ Recursos determinados } & Apoyo en gestión a gobiernos subnacionales & 0,00 \\
\hline & Canon forestal & 0,00 \\
\hline & Canon gasífero & 2,61 \\
\hline & Canon hidroenergético & 0,20 \\
\hline & Canon minero & 3,72 \\
\hline & Canon pesquero & 0,15 \\
\hline & Canon petrolero & 2,25 \\
\hline & Focam & 0,78 \\
\hline & Participaciones & 0,58 \\
\hline & Regalías mineras & 0,36 \\
\hline & Rentas de aduana & 0,95 \\
\hline & Transferencias entre gobiernos e instituciones & 0,00 \\
\hline & Transferencias a fondos o programas específicos & 0,74 \\
\hline & Subtotal & 12,35 \\
\hline \multirow{4}{*}{ Recursos ordinarios } & Apoyo en gestión a gobiernos subnacionales & 0,00 \\
\hline & Transferencias a fondos o programas específicos & 75,58 \\
\hline & Transferencias entre gobiernos e instituciones & 7,39 \\
\hline & Subtotal & 82,97 \\
\hline \multicolumn{2}{|r|}{ Total general** } & $21.205,37$ \\
\hline
\end{tabular}

*Incluye los 25 gobiernos regionales, más Lima Metropolitana. **En millones de S/.

Fuente: elaboración del autor a partir de datos del MEF, Portal de Transparencia.

Finalmente, los recursos en coparticipación de impuestos representaron el $13,11 \%$ de los fondos transferidos, donde el $58,4 \%$ lo concentraron los municipios distritales; sin embargo, para este nivel de gobierno representaron tan solo el $25 \%$ de sus recursos transferidos, a diferencia de los municipios provinciales, para los cuales representó el $37,6 \%$ de sus recursos transferidos.
A efectos de determinar la equidad en la distribución de los ingresos por transferencias, se volverá a efectuar el análisis inicial, esta vez desde las tres categorías de ingresos reclasificados individualmente: a) las transferencias discrecionales mayormente condicionadas, b) las transferencias provenientes de la explotación económica de recursos naturales y c) las transferencias de impuestos en coparticipación. 
Tabla 10.

Recursos transferidos según reclasificación de fuente de financiamiento en el Perú, 2013*

\begin{tabular}{|c|c|c|c|c|}
\hline Fuente reclasificada para el análisis & $\begin{array}{l}\text { Gobiernos } \\
\text { regionales }\end{array}$ & Provinciales & Distritales & Total \\
\hline Apoyo en gestión a gobiernos subnacionales & 0,01 & 6,77 & 5,78 & 2,77 \\
\hline Transferencias a fondos o programas específicos & 78,95 & 15,51 & 18,47 & 51,15 \\
\hline Transferencias entre gobiernos e instituciones & 9,43 & 14,60 & 9,58 & 10,23 \\
\hline Transferencias discrecionales mayormente condicionadas & 88,39 & 36,88 & 33,83 & 64,14 \\
\hline Canon forestal & 0,00 & 0,00 & 0,00 & 0,00 \\
\hline Canon gasífero & 2,61 & 4,93 & 13,08 & 6,16 \\
\hline Canon hidroenergético & 0,20 & 0,45 & 1,13 & 0,52 \\
\hline Canon minero & 3,72 & 12,70 & 18,52 & 9,57 \\
\hline Canon pesquero & 0,15 & 0,52 & 0,57 & 0,33 \\
\hline Canon petrolero & 2,25 & 5,90 & 3,95 & 3,31 \\
\hline Focam & 0,78 & 2,83 & 1,36 & 1,26 \\
\hline Regalías mineras & 0,36 & 1,87 & 2,57 & 1,26 \\
\hline Participaciones & 0,58 & 0,15 & 0,00 & 0,34 \\
\hline $\begin{array}{c}\text { Transferencias por explotación económica } \\
\text { de recursos naturales }\end{array}$ & 10,66 & 29,35 & 41,19 & 22,75 \\
\hline Impuestos municipales (casinos y tragamonedas) & 0,00 & 1,91 & 0,43 & 0,41 \\
\hline FONCOMÚN & 0,00 & 30,83 & 23,14 & 11,59 \\
\hline Rentas de aduana & 0,95 & 1,03 & 1,42 & 1,10 \\
\hline Transferencias de impuestos en coparticipación & 0,95 & 33,76 & 24,98 & 13,11 \\
\hline Total general ${ }^{* \star}$ & $21.205,37$ & $5.655,82$ & $11.875,94$ & $38.737,13$ \\
\hline
\end{tabular}

*Incluye 1838 gobiernos locales. ${ }^{* *}$ En millones de S./.

Fuente: elaboración del autor a partir de datos del MEF, Portal de Transparencia.

\section{Transferencias discrecionales mayormente condicionadas}

En el gráfico 8 se observa que las curvas de Lorenz son más convexas para el caso de dichas transferencias, lo que denota que existe una mayor desigualdad en la distribución de dichos recursos.

Esto se corrobora nuevamente con los índices de desigualdad, que, como se aprecia en la tabla 11, aumentan en todos los niveles de gobierno subnacionales, pero en especial para los gobiernos locales. En promedio, en los municipios distritales aumenta en $59,4 \%$, en los municipios provinciales aumenta en $62,6 \%$ y en los gobiernos regionales aumenta solo en $3,4 \%$. Respecto del coeficiente de Gini de ingresos de la población nacional, en los municipios distritales y provinciales son mayores a este en $34,2 \%$ y $16,5 \%$, pero $48,9 \%$ menor en los gobiernos regionales.
Gráfico 8.

Curva de Lorenz: transferencias discrecionales mayormente condicionadas, 2013

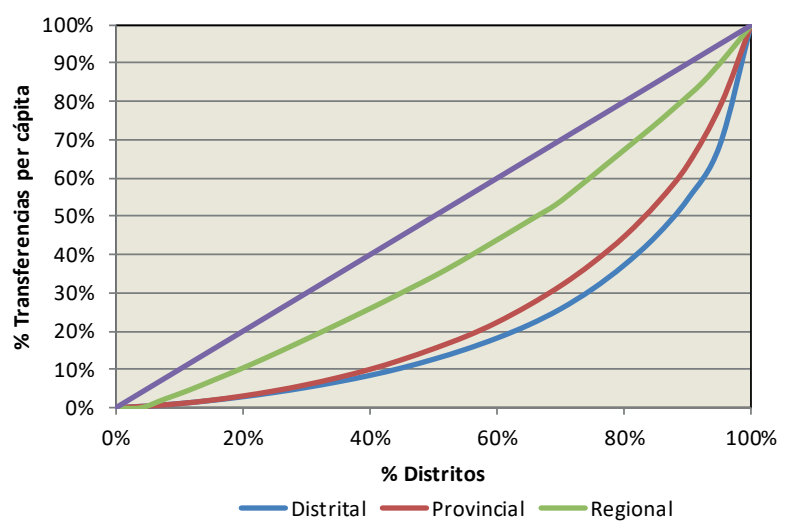

Fuente: elaboración del autor. 
Tabla 11.

Índices de desigualdad de transferencias discrecionales mayormente condicionadas por nivel de gobierno subnacional en el Perú, $2013^{*}$

\begin{tabular}{|c|c|c|c|}
\hline \multirow{2}{*}{ Índices } & \multicolumn{3}{|c|}{ Por nivel de gobierno subnacional } \\
\cline { 2 - 4 } & Distrital & Provincial & 0,4291 \\
\hline Coeficiente de variación & 1,6239 & 1,0643 & 0,2247 \\
\hline Índice de Gini & 0,5904 & 0,5127 & 0,0303 \\
\hline Índice de Theil normalizado & 0,0908 & 0,0846 & 0,5510 \\
\hline Índice de Atkinson** & 0,6163 & 0,5320 & 26 \\
\hline
\end{tabular}

*Las transferencias no obligatorias per cápita se utilizan como unidad de análisis. ${ }^{* *}$ Con parámetro de aversión a la desigualdad de 1,5. ${ }^{* * *}$ El total de gobiernos subnacionales corresponde a aquellos de los que se tenía total información. Fuente: elaboración del autor a partir de datos del MEF e INEI.

Perú: transferencias distritales discrecionales mayormente condicionadas por zonas geográficas

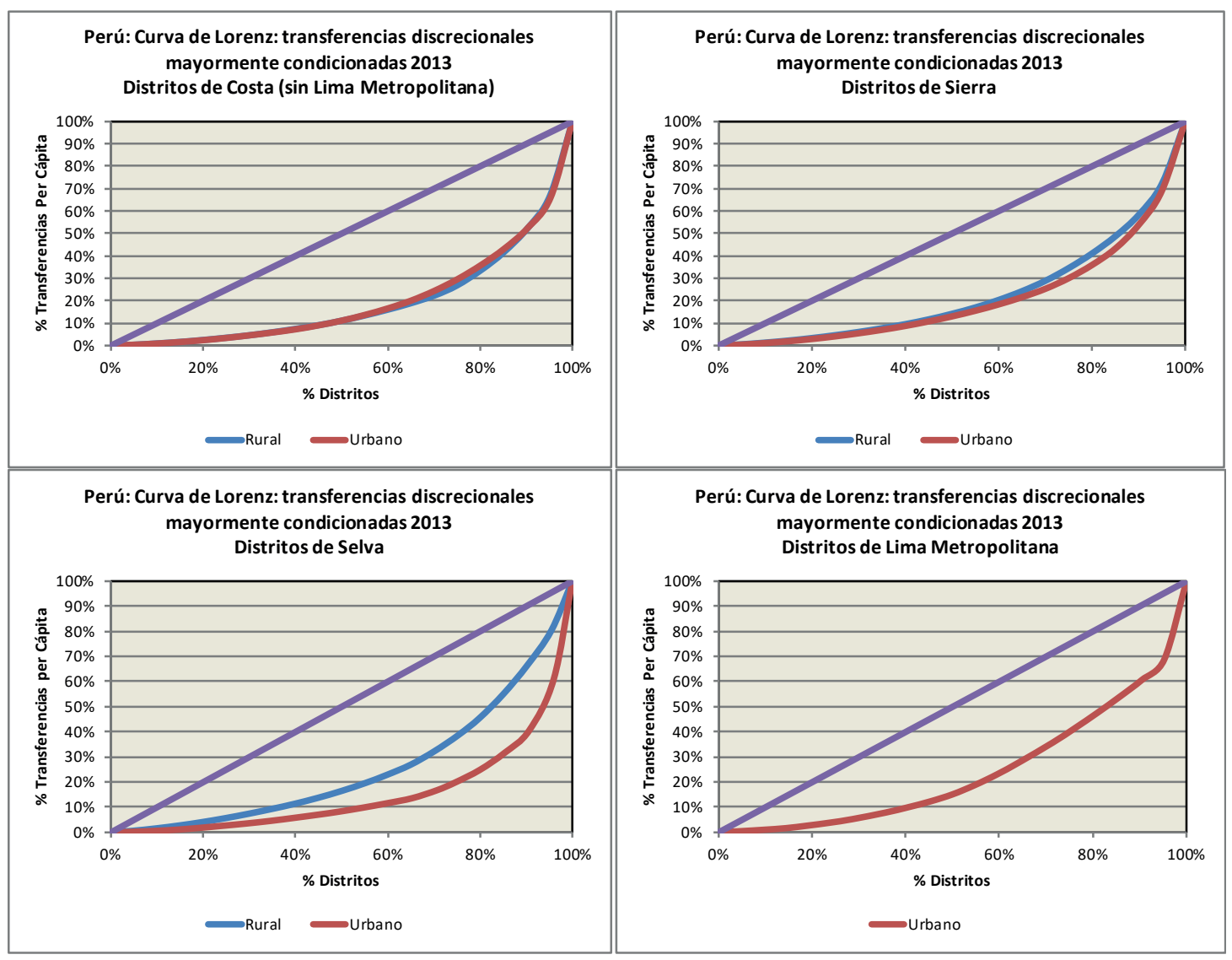

Fuente: elaboración del autor. 
Tabla 12.

Índices de desigualdad de transferencias discrecionales mayormente condicionadas a municipios distritales en el Perú, 2013*

\begin{tabular}{|c|c|c|c|c|c|c|c|}
\hline \multirow{2}{*}{ Índices } & \multicolumn{7}{|c|}{ Por región geográfica y categoría de urbanización } \\
\cline { 2 - 9 } & \multicolumn{2}{|c|}{ Costa } & \multicolumn{2}{c|}{ Sierra } & \multicolumn{2}{c|}{ Selva } & Lima Metropolitana \\
\cline { 2 - 9 } & Urbana & Rural & Urbana & Rural & Urbana & Rural & Urbana \\
\hline Coeficiente de variación & 1,7205 & 1,6845 & 1,4390 & 1,3440 & 2,3792 & 1,0796 & 1,3771 \\
\hline Índice de Gini & 0,6098 & 0,6182 & 0,5851 & 0,5477 & 0,6984 & 0,4937 & 0,5183 \\
\hline Índice de Theil normalizado & 0,1307 & 0,1419 & 0,1132 & 0,0857 & 0,2498 & 0,0835 & 0,1438 \\
\hline índice de Atkinson** & 0,6340 & 0,6361 & 0,5825 & 0,5355 & 0,7243 & 0,4712 & 0,5364 \\
\hline Total de gobiernos evaluados*** & 278 & 188 & 281 & 624 & 75 & 154 & 42 \\
\hline
\end{tabular}

"Las transferencias no obligatorias per cápita se utilizan como unidad de análisis. ${ }^{* *}$ Con parámetro de aversión a la desigualdad de 1,5. ${ }^{* * *}$ El total de gobiernos subnacionales corresponde a aquellos de se tenía total información.

Fuente: elaboración del autor a partir de datos del MEF e INEI.

Asimismo, si se desagregan los municipios distritales por región geográfica y tipología ruralurbana, en el gráfico 9 se puede observar que las curvas de Lorenz tienden a ser más convexas y presentan una pendiente mayor en los gobiernos subnacionales con niveles más elevados de transferencias.

Por su parte, los índices que se presentan en la tabla 12 demuestran que la desigualdad aumenta con respecto a las transferencias totales en todas las regiones, excepto en la selva rural, donde se reduce; sin embargo, el incremento es más acentuado en la costa y sierra rurales. En promedio, la desigualdad en la costa urbana aumenta en $61,7 \%$, en la costa rural aumenta en $95,1 \%$, en la sierra urbana lo hace en $35,9 \%$, en la sierra rural aumenta en $93,4 \%$, en la selva urbana se incrementa en $47,8 \%$, en la selva rural lo hace en $12,5 \%$ y en Lima Metropolitana el aumento es de 14,2\%.

\section{Transferencias provenientes de la explotación económica de recursos naturales}

En cuanto a este tipo de transferencias, el panorama es mucho más complejo. Las curvas de Lorenz que se presentan en el gráfico 10 muestran que la desigualdad de las transferencias provenientes de dicha fuente de recursos se vuelve mucho más convexa y con una pendiente muy pronunciada, sobre todo en los GL.

Gráfico 10.

Curva de Lorenz de transferencia de la explotación económica de recursos naturales en el Perú, 2013

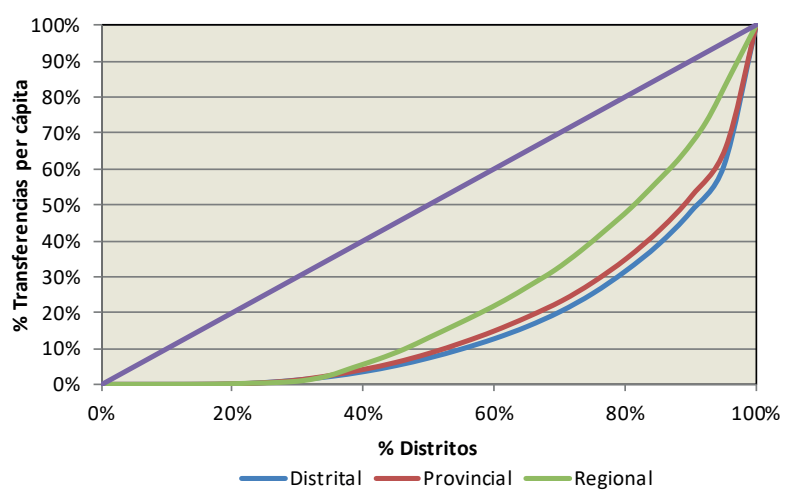

Fuente: elaboración del autor

Todos los índices utilizados para su cuantificación aumentan considerablemente, como se muestra en la tabla 13. Se observan incrementos promedio superiores a $122,3 \%$ para el caso de los municipios distritales, de 192,4\% para el caso de los municipios provinciales y de más de $201,3 \%$ en el caso de los gobiernos regionales. 
Tabla 13.

Índices de desigualdad de transferencias por explotación de recursos naturales en Perú, 2013*

\begin{tabular}{|c|c|c|c|}
\hline \multirow{2}{*}{ Índices } & \multicolumn{3}{|c|}{ Por nivel de gobierno subnacional } \\
\cline { 2 - 4 } & Distrital & Provincial & Regional \\
\hline Coeficiente de variación & 2,1752 & 2,1472 & 1,0106 \\
\hline Índice de Gini & 0,6750 & 0,6435 & 0,5265 \\
\hline $\begin{array}{c}\text { Índice de Theil } \\
\text { normalizado }\end{array}$ & 0,1303 & 0,1678 & 0,1542 \\
\hline $\begin{array}{c}\text { Índice de Atkinson** } \\
\begin{array}{c}\text { Total de gobiernos } \\
\text { evaluados*** }\end{array}\end{array}$ & 0,9960 & 0,9932 & 0,9792 \\
\hline
\end{tabular}

* Las transferencias por exploración de RN per cápita se utilizan como unidad de análisis. ${ }^{*}$ Con parámetro de aversión a la desigualdad de 1,5. ${ }^{* *}$ El total de gobiernos subnacionales evaluados corresponde a aquellos de los que se tenía total información.

Fuente: elaboración del autor a partir de datos de MEF e INEI.
Con respecto al coeficiente de Gini de ingresos de la población, estos son mayores en los municipios distritales y provinciales $(53,4 \%$ y $46,3 \%$, respectivamente) y en los gobiernos regionales es mayor (19,7\%). Este resultado lleva a concluir que la desigualdad en los GR como producto de las transferencias provenientes de recursos naturales no es tan acentuada como se especula; es más bien en los GL donde se crean las mayores desigualdades, dado que son pocos los distritos que reciben la mayor parte de estos recursos comparativamente, incluso mucho más de lo que pueden gastar.

Por otra parte, si se desagregan los municipios distritales por región geográfica y categoría de urbanización, las curvas de Lorenz que se muestran en el gráfico 11 presentan una mayor desigualdad. La situación empeora en particular en los distritos de la sierra urbana y selva urbana y

\section{Gráfico 11.}

Transferencias distritales de la explotación económica de recursos naturales por zonas geográficas en el Perú, 2013
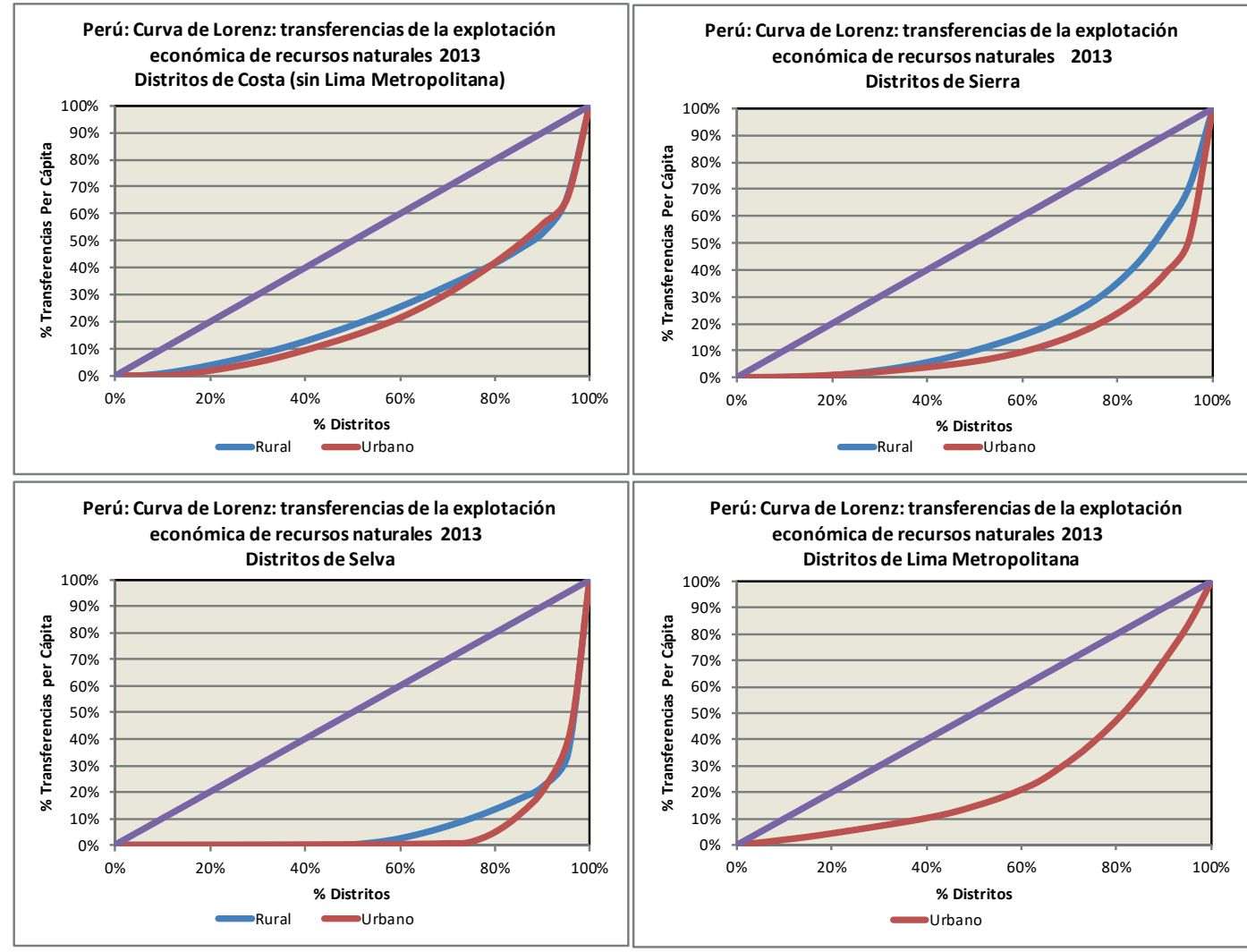

Fuente: elaboración del autor. 
Tabla 14.

Índices de desigualdad de transferencias por explotación de recursos naturales en municipios distritales del Perú, 2013*

\begin{tabular}{|c|c|c|c|c|c|c|c|}
\hline \multirow{2}{*}{ Índices } & \multicolumn{6}{|c|}{ Por región geográfica y categoría de urbanización } \\
\cline { 2 - 9 } & \multicolumn{2}{|c|}{ Costa } & \multicolumn{2}{|c|}{ Sierra } & \multicolumn{2}{|c|}{ Selva } & Lima Metropolitana \\
\cline { 2 - 9 } & Urbana & Rural & Urbana & Rural & Urbana & Rural & Urbana \\
\hline Coeficiente de variación & 1,9534 & 1,6184 & 2,7683 & 1,5530 & 3,3883 & 3,5615 & 0,9532 \\
\hline Índice de Gini & 0,5614 & 0,5249 & 0,7321 & 0,6186 & 0,8852 & 0,8531 & 0,4896 \\
\hline Índice de Theil normalizado & 0,1277 & 0,1199 & 0,2166 & 0,1120 & 0,4537 & 0,3717 & 0,1062 \\
\hline Índice de Atkinson** & 0,9893 & 0,9761 & 0,9908 & 0,9756 & 0,9974 & 0,9997 & 0,4759 \\
\hline Total de gobiernos evaluados*** & 278 & 188 & 281 & 624 & 75 & 154 & 42 \\
\hline
\end{tabular}

*Las transferencias por exploración de RN per cápita se utilizan como unidad de análisis. **Con parámetro de aversión a la desigualdad de $1,5 .{ }^{* * *}$ El total de gobiernos subnacionales evaluados corresponde a aquellos de los que se tenía total información.

Fuente: elaboración del autor a partir de datos de MEF e INEI

rural, que reciben las mayores transferencias por canon petrolero y minero, respectivamente.

Además, como se observa en la tabla 14, los índices cuantitativos aumentan en promedio para el caso de la costa urbana en $85,2 \%$, en la costa rural en $106,4 \%$, en la sierra urbana aumentan en $131,4 \%$, en la sierra rural lo hacen en $165,8 \%$, en la selva urbana en $120,4 \%$, en la selva rural en $216 \%$ y en Lima Metropolitana se reduce en 7,2\%.

\section{Transferencias de impuestos en coparticipación}

Las transferencias de impuestos en coparticipación, que, como vimos, provienen principalmente del FONCOMÚN e impuestos municipales de casinos y tragamonedas para el caso de los $\mathrm{GL}$, y de las rentas de aduanas para el caso de los GR, evidencian una situación contraria para cada uno de estos niveles de gobierno. Así, para los GL representan una mejoría en cuanto a su desigualdad, en cambio evidencian un deterioro para el caso de los GR. Esto se puede apreciar en el gráfico 12 de las curvas de Lorenz por nivel de gobierno, que mejoran para los gobiernos locales y empeoran en extremo para los gobiernos regionales.
Gráfico 12

Curva de Lorenz de transferencias de impuestos de coparticipación en el Perú, 2013

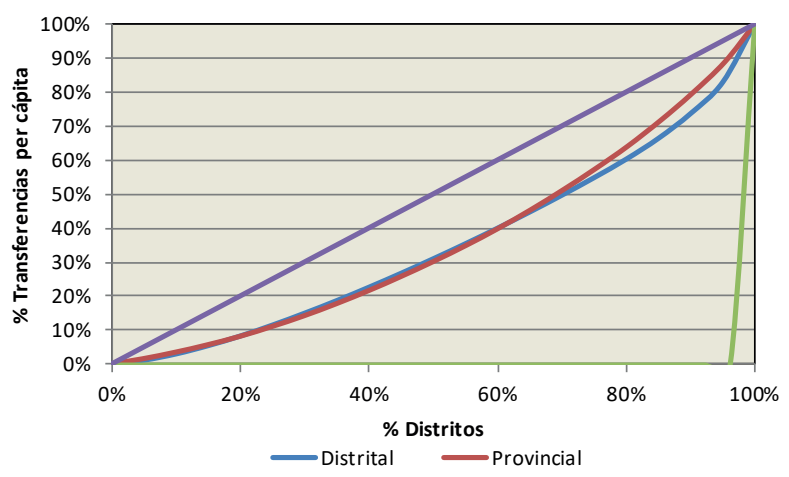

Fuente: elaboración del autor.

Los índices de desigualdad corroboran esta situación, ya que como se observa en la tabla 15, los índices de los gobiernos locales mejoran respecto de los índices de las transferencias totales evaluadas, que se reducen en $34,3 \%$ para los municipios distritales y en $34,2 \%$ para los municipios provinciales. Esto se debe a la forma como se distribuyen los recursos del FONCOMUN, que está muy ligada a los indicadores de población. Sin embargo, los índices de los GR empeoran extremadamente, fundamentalmente porque solo el GR del callao recibió los recursos de rentas de aduana. 
Tabla 15.

Índices de desigualdad de transferencias de impuestos en coparticipación en el Perú, 2013*

\begin{tabular}{|c|c|c|c|}
\hline \multirow{2}{*}{ Índices } & \multicolumn{3}{|c|}{ Por nivel de gobierno subnacional } \\
\cline { 2 - 4 } & Distrital & Provincial & Regional \\
\hline Coeficiente de variación & 0,8383 & 0,5293 & 5,0990 \\
\hline Índice de Gini & 0,3034 & 0,2826 & 0,9615 \\
\hline $\begin{array}{c}\text { Índice de Theil } \\
\text { normalizado }\end{array}$ & 0,0266 & 0,0244 & 1,0000 \\
\hline $\begin{array}{c}\text { Índice de Atkinson** } \\
\text { Total de gobiernos } \\
\text { evaluados*** }\end{array}$ & 0,2270 & 0,1849 & \\
\hline
\end{tabular}

* Las transferencias por impuesto en coparticipación per cápita se utiliza como unidad de análisis. **Con parámetro de aversión a la desigualdad de 1,5. ${ }^{* *}$ El total de gobiernos subnacionales evaluados corresponde a aquellos de los que se tenía total información.

Fuente: elaboración del autor a partir de datos de MEF e INEI.

Desagregando los distritos por región y clasificación de urbanidad, las curvas de Lorenz que se presentan en el gráfico 13 muestran que la desigualdad se reduce en los municipios de sierra y selva rural, aunque empeora ligeramente en los distritos de la costa urbana y de Lima Metropolitana.

De hecho, los índices cuantitativos de desigualdad que se presentan en la tabla 16 demuestran que hay una reducción respecto de los índices de transferencias totales en la costa rural en $23,8 \%$, en la sierra urbana en $35 \%$, en la sierra rural en $66,4 \%$, en la selva urbana en $56,6 \%$ y en la selva rural en $59 \%$. Sin embargo, en la costa urbana aumenta en $11,4 \%$ y en Lima Metropolitana lo hace en $13,8 \%$.

Una explicación de dicho fenómeno es que el impuesto a los juegos de casinos y tragamonedas se encuentra ubicado principalmente en los distritos de mayor concentración poblacional y con mayores atractivos turísticos, pero son escasos en los distritos de la selva y sierra, más aún del ámbito rural.

Como es obvio suponer, este análisis de la distribución aparenta ser incompleto en la medida en que la distribución suele responder a la propia heterogeneidad de las circunscripciones en cuanto a sus características territoriales, sociales, económicas; las restricciones institucionales de cada tipo de transferencias; las prioridades de desarrollo nacional; la capacidad fiscal, y las necesidades de recursos de cada circunscripción; pero evidencia una primera aproximación a su distribución. En tal sentido, es necesario medir dicha desigualdad a partir de índices globales que permitan determinar si ello se corrobora; sin embargo, primero deberá lograrse un nivel de desagregación mayor que permita homogenizar ligeramente la información para saber que se está midiendo la misma unidad de análisis.

Por esta razón, en los siguientes párrafos se bosquejará una forma de distribución que se acerque a una función de evaluación social basada en variables socioeconómicas.

\section{Desigualdad normativa bajo una función de evaluación social}

Una evaluación de las tranferencias totales atendiendo a criterios sociales, construida de la forma que se explicó en el subcapítulo de diseño metodológico, permite comparar cuál debería ser la distribución de los recursos versus la distribución actual real recibida. Para el caso de los municipios distritales, puede decirse que existen 116 municipios provinciales que, atendiendo a sus necesidades sociales, debieron recibir en 2013 más de lo que recibieron, en tanto 76 deberían recibir menos de lo que reciben actualmente.

En el gráfico 14 se puede observar la dispersión de las tranferencias totales recibidas en el 2013 versus las tranferencias totales atendiendo a criterios de valoración social. Todos los puntos identifican las diversas circunscripciones territoriales; los que estan por debajo de la linea punteada son aquellos municipios que debieron recibir mayor cantidad de tranferencias fiscales (son la mayor parte), y los que se encuentran por encima de la linea punteada son todos aquellos municipios que debieron recibir menos recursos según criterios de evaluación social. 

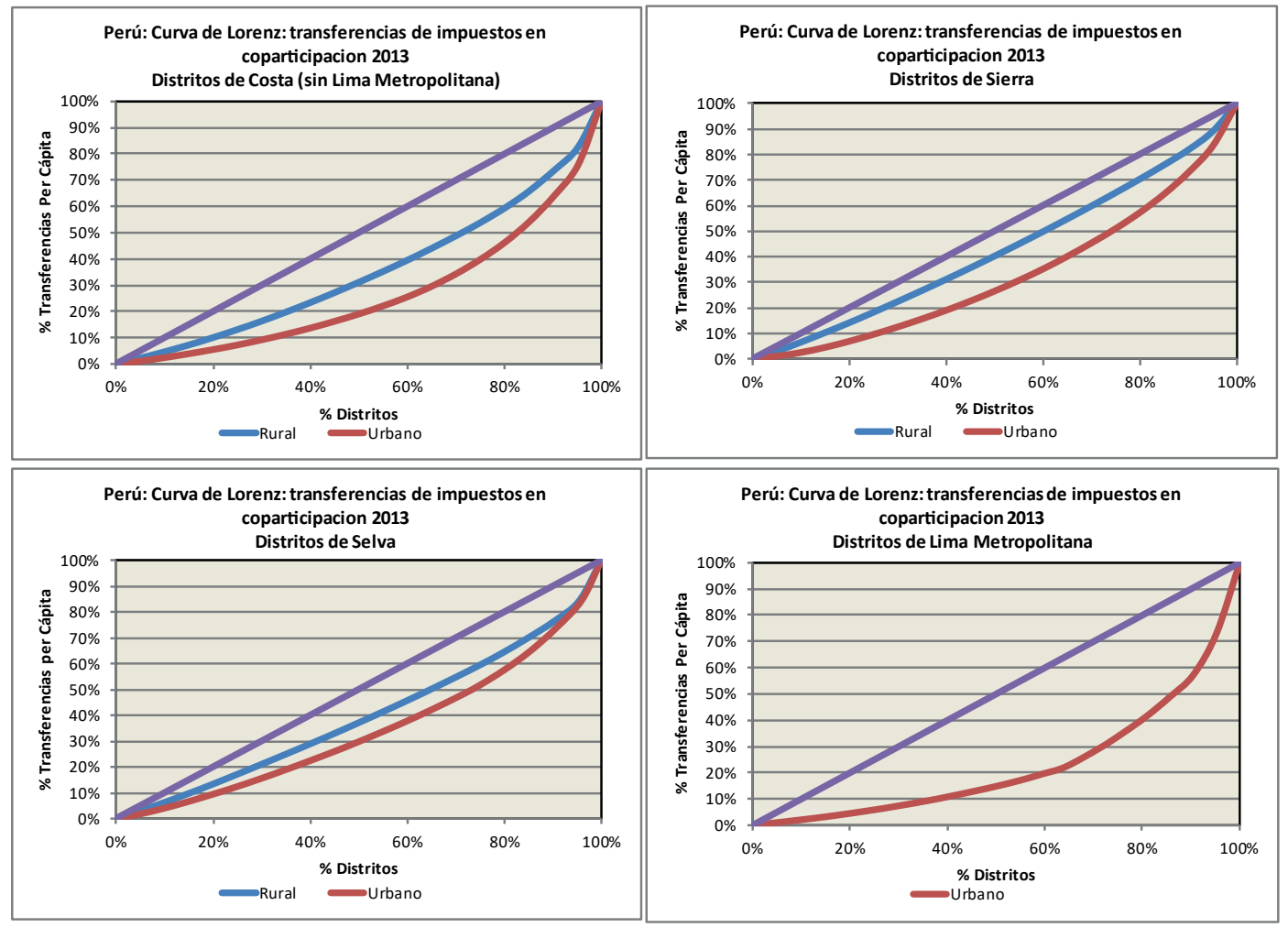

Fuente: elaboración del autor.

Tabla 16.

Índices de desigualdad de transferencias de impuestos en coparticipación de municipios distritales en Perú, 2013*

\begin{tabular}{|c|c|c|c|c|c|c|c|}
\hline \multirow{2}{*}{ Índices } & \multicolumn{7}{|c|}{ Por región geográfica y categoría de urbanización } \\
\cline { 2 - 9 } & \multicolumn{2}{|c|}{ Costa } & \multicolumn{2}{|c|}{ Sierra } & \multicolumn{2}{c|}{ Selva } & Lima Metropolitana \\
\cline { 2 - 9 } & Urbana & Rural & Urbana & Rural & Urbana & Rural & Urbana \\
\hline Coeficiente de variación & 1,3291 & 0,9739 & 0,7683 & 0,3641 & 0,7251 & 0,6250 & 1,3501 \\
\hline Índice de Gini & 0,4754 & 0,2973 & 0,3524 & 0,1528 & 0,3166 & 0,2128 & 0,5437 \\
\hline Índice de Theil normalizado & 0,0788 & 0,0409 & 0,0389 & 0,0079 & 0,0437 & 0,0240 & 0,1486 \\
\hline Índice de Atkinson** & 0,4036 & 0,1826 & 0,2728 & 0,0594 & 0,2024 & 0,1106 & 0,4997 \\
\hline Total de gobiernos evaluados*** & 278 & 188 & 281 & 624 & 75 & 154 & 42 \\
\hline
\end{tabular}

*Las transferencias por impuesto en coparticipación per cápita se utiliza como unidad de análisis. **Con parámetro de aversión a la desigualdad de 1,5.**El total de gobiernos subnacionales evaluados corresponde a aquellos de los que se tenía total información. Fuente: elaboración del autor a partir de datos de MEF e INEI. 
Gráfico 14.

Dispersión de transferencias reales versus transferencias por función de evaluación social en provincias del Perú, 2013

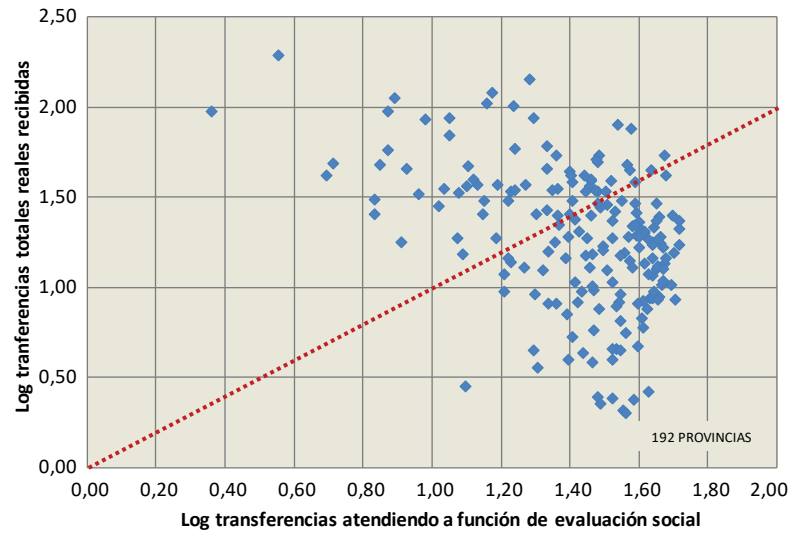

Fuente: elaboración del autor.

Para el caso de los municipios distritales, puede verse en el gráfico 15 que existen 1.132 municipios distritales que, atendiendo a sus necesidades sociales, debieron recibir en el 2013 más de lo que recibieron, y 509 deberían recibir menos de lo que reciben actualmente. En el gráfico se puede observar la dispersión de las tranferencias totales recibidas en el año en mención versus las tranferencias totales atendiendo a criterios de valoración social. Al igual que el análisis gráfico de los municipios provinciales, los que se encuentran por debajo de la linea punteada son aquellos municipios distritales que debieron recibir mayor cantidad de tranferencias fiscales (son la mayor parte); los que se encuentran por encima son todos aquellos que debieron recibir menos recursos según criterios de evaluación social.

Con estos resultados se verifica, entonces, que existe una gran heterogeneidad en la distribución de las transferencias fiscales; además, utilizando un criterio de evaluación social, se puede señalar que existe una inequitativa asignación de los recursos fiscales en los gobiernos locales, lo que hace urgente un replanteamiento de las transferencias fiscales a fin de que muestren una mayor equidad.

Es cierto que un análisis de la heterogeneidad debería completarse con la inclusión de la capacidad fiscal de cada circunscripción territorial.
No obstante, la existencia de una gran disparidad fiscal positiva en la mayor parte de las circunscripciones gubernamentales hace innecesario un análisis en esa línea. De hecho, hay departamentos financieramente inviables en un proceso integral de descentralización fiscal (aquellos incapaces de autofinanciar sus gastos con los recursos propios que puedan generar), donde una estimación del "mapa tributario" realizado por la Asamblea Nacional de Gobiernos Regionales (ANGR) del $2007^{19}$ visualizó solo ocho (8) de los 24 departamentos con disparidad regional negativa, y donde siete (7) de ellos solo cubren ligeramente sus gastos.

Gráfico 15.

Dispersión de transferencias reales versus transferencias por función de evaluaicón social en distritos del Perú, 2013

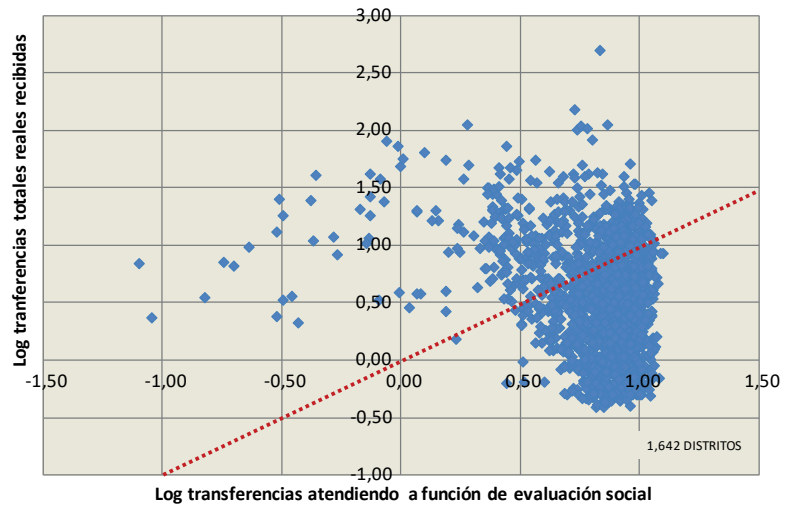

Fuente: elaboración del autor.

Adicionalmente, aunque no es el motivo de esta investigación, una evaluación de la equidad horizontal mostraría la insuficiencia de recursos de todas las circunscripciones para la provisión de servicios públicos; donde los ingresos tributarios del GN concentraron en los últimos 5 años (20092013) casi el $96 \%$ de los recursos tributarios y los gobiernos subnacionales únicamente cerca del $4 \%$; y solo cuando se incorporan todos los recursos no financieros - es decir, sin incluir el endeudamiento y los saldos de balance-, dicha participación

19 En dicho documento se encuentra que la participación individual en la generación de ingresos es mayor a su participación en el gasto público solo en el caso de Lima y Callao, Arequipa, La Libertad, Pasco, Ancash, Lambayeque, Ica y Moquegua. 
aumenta hasta el $75,9 \%$ para el conjunto de los gobiernos subnacionales. Ello comprueba el enorme peso que tienen las transferencias fiscales en las finanzas subnacionales.

\section{CONCLUSIÓN}

Una de las grandes reformas pendientes en el Perú es la de completar el proceso de descentralización fiscal, y en ese ánimo, esta investigación ha pretendido ofrecer un panorama de las transferencias fiscales a los gobiernos subnacionales.
La conclusión de la presente investigación es que existe una gran inequidad horizontal en la distribución de transferencias a los gobiernos subnacionales, la cual se evidencia cuando se realiza un análisis de la distribución de las transferencias a partir de variables sociales. Los índices, vistos desde diversos ángulos de clasificación del ingreso y de las características de los propios gobiernos subnacionales, confirman que existe un nivel importante de inequidad horizontal en la distribución de dichos recursos.

\section{REFERENCIAS}

1. Aghón, G. (1999). Descentralización fiscal: tendencias y tareas pendientes. Bogotá: Secretaría de Hacienda de Bogotá.

2. Aghón, G. (2000). Los retos pendientes de la descentralización fiscal en América Latina y el Caribe. Seminario Internacional "Avances y dificultades de la descentralización fiscal en El Salvador, Nicaragua, Costa Rica y República Dominicana. Managua.

3. Aguilar, G. y Morales, R. (2005). Las transferencias intergubernamentales, el esfuerzo fiscal y el nivel de actividad. Lima: Instituto de Estudios Peruanos.

4. Albi, E., González-Páramo, J. M., Zubiri, I. (2004). Economía pública I y II. Madrid: Ariel.

5. Alvarado, B. (2003). Análisis de los efectos y usos de las transferencias intergubernamentales. Lima: Centro de Investigación de la Universidad del Pacífico y CIES.

6. Alvarado, B. (2008). Descentralización fiscal en el Perú: contexto y exploración del desempeño municipal. Lima: Banco Interamericano de Desarrollo.

7. Ausejo Castillo, F. (2014). Evaluación del proceso de transferencia de competencias sectoriales a los gobiernos regionales y locales con enfoque de gestión descentralizada de servicios públicos. Lima: Secretaría de Descentralización.

8. Azpur, J., Ballón, E., Chirinos, L., Baca, E. y Távara, G. (2006). La descentralización en el Perú: un balance de lo avanzado y una propuesta de agenda para una reforma imprescindible. Cuadernos Descentralistas, 18, 9-29.

9. Banco Mundial (2000). Development in Latin America and The Caribbean 1999. Decentralization and Accountability of the Public Sector. Washington: Autor.

10. Blöchliger, H. y Petzold, O. (2009). Tratando de encontrar la línea divisoria entre tributos compartidos y trans ferencias: una investigación estadística. Recuperado de https://www.oecd.org/tax/federalism/43959055.pdf

11. Boadway, R. y Shah, A. (Eds.) (2009). Transferencias fiscales intergubernamentales. Principios y prácticas. Bogotá: Banco Mundial.

12. Bonet, J. (2004). Descentralización fiscal y disparidades en el ingreso regional: la experiencia colombiana. Bogotá: Banco de la República.

13. Coronado Quintanilla, J. (2009). Sostenibilidad de las finanzas en gobiernos subnacionales. Londres: Debt Relief International. 
14. Del Valle, M. (2010). Descentralización y sostenibilidad fiscal subnacional: los casos de Colombia y Perú. Washington: Banco Interamericano de Desarrollo.

15. Fisher, R.C. (1982). Income and grant effects on local expenditure: The flypaper effect and other difficulties. Journal of Urban Economics, 12, 324-345.

16. Fondo Monetario Internacional (2001). Manual de estadísticas de las finanzas Públicas. Washington: Autor.

17. Forum of Federations (2005). Handbook of Federal Countries, 2005. Montreal: McGill-Queen's University Press.

18. Francke, P. (2002). Análisis de los criterios de asignación de los recursos públicos que son transferidos desde el Gobierno Central a los Gobiernos Subnacionales. Lima: Ministerio de Economía y Finanzas.

19. Gil-Serrate, R. y López-Laborda, J. (2005). Modelling tax decentralization and regional growth. Madrid: Instituto de Estudios Fiscales.

20. Goerlich, F. J. y Villar, A. (2009). Desigualdad y bienestar social: de la teoría a la práctica(1. a ed.). Bilbao: Fundación BBVA.

21. Gómez, J. L. y Sepúlveda, C. (2008). El Sistema de Transferencias Intergubernamentales en el Perú: una evaluación preliminar. Lima: Red de Municipalidades Rurales del Perú.

22. Gonzales de Olarte, E. (2004). La difícil descentralización fiscal en el Perú: teoría y práctica. Lima: Instituto de Estudios Peruanos.

23. Gramlich, E. M. (1977). A review of the theory of intergovernmental grants. En W. E. Oates (Ed.), The political economy of fiscal federalism. Lexington: Heath.

24. Gutiérrez, J. A., Rodríguez González, C. y Castro Torres, J. V. (2000). Ajuste fiscal y sistema de transferencias: serias repercusiones de un análisis incompleto. Bogotá: Secretaría de Hacienda.

25. Hernández, F. (1999). Los dilemas de la descentralización fiscal en México, 1995-2000. Recuperado de http:// www.indetec.gob.mx/cnh/Interes/DocsInt/Doc04.pdf

26. Hernández, F.et al. (1999). Fiscal descentralization in Mexico: The Bailout Problem. Washington: Banco Interamericano de Desarrollo.

27. Hines, J. R. y Thaler, R. H. (1995). Anomalies: The Flypaper effect. Journal of Economic Perspectives, 9(4), 217-226.

28. Inman, R. P. (1979). The fiscal performance of local governments: An interpretative review. En P. Mieszkowski y M. Staszheim (Eds.), Current issues in urban economics. Baltimore: Johns Hopkins University Press.

29. Iregui, A. M., Ramos, J. y Saavedra, L.A. (2001). Análisis de la descentralización fiscal en Colombia. Bogotá: Banco de la República.

30. Lagos Rodríguez, G. (2001). Una revisión de la literatura del federalismo fiscal. Notas sobre la equidad interterritorial. Ciudad Real: Universidad de Castilla-La Mancha.

31. Larios, J., Alvarado, B. y Conterno, E. (2004). Descentralización fiscal: análisis conceptual y revisión de experiencias en nueve países. Lima: PRODES.

32. Martínez Vázquez, J. y Boex, J. (1997). Fiscal capacity: an overview of concepts and measurement issues and their applicability in the Russian Federation. Georgia: Georgia State University.

33. Ministerio de Economía y Finanzas del Perú (2002). Procesos de descentralización en Latinoamérica: Colombia, México, Chile y Perú. Lima: Autor. 
34. Ministerio del Interior de Chile, Subsecretaría de Desarrollo Regional y Administrativo (SUBDERE) (2006). Memoria de la descentralización 2000-2006. Santiago de Chile: Autor.

35. Oates, W. E. (1999). An essay on fiscal federalism. Journal of Economic Literature, 37(3),1120-1149.

36. Programa de las Naciones Unidas para el Desarrollo (PNUD) y Servicio Holandés de Cooperación al Desarrollo (SNV) (2006). Descentralización con ciudadanía en el Perú: Dialogo con actores regionales. Lima: Autor.

37. Polése, M. (1998). Economía urbana y regional. Introducción a la relación entre territorio y desarrollo (1. ${ }^{\text {a }}$ ed.). Costa Rica: Libro Universitario Regional.

38. Porras Vallejo, O.A. (2005). Descentralización en Colombia: estado actual y perspectivas. Universidad Nacional de Colombia, CID, PRODESPAZ, GTZ, USAID y ACCI, Colombia.

39. PRODES (2007). El proceso de descentralización: balance y agenda a septiembre de 2007. Lima: PRODES-USAID.

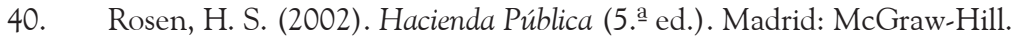

41. Ruiz Huerta, J. (1988). Federalismo fiscal y descentralización del sector público español. Madrid: Instituto de Estudios Fiscales.

42. Shack, N. (2006). Presupuestar en Perú. Santiago de Chile: Instituto Latinoamericano y del Caribe de Planificación Económica y Social.

43. Shah, A.(1994a). A fiscal need approach to equalization transfers in a decentralized federation (Working Paper 1289). Washington: Banco Mundial.

44. Shah, A.(1994b). The reform of intergovernmental fiscal relations in developing and emerging market economies. Washington: Banco Mundial.

45. Shah, A. (2006). A practitioner's guide to intergovernmental fiscal transfers (Working Paper 4039). Washington: Banco Mundial.

46. Sobarzo, H. (2003). México: Estudio sobre la capacidad fiscal y tributaria y el esfuerzo tributario de los gobiernos estatales en México. Recuperado de http://www.indetec.gob.mx/cnh/Interes/DocsInt/Sobarzo.pdf

47. Stiglitz, J.E. (2000). La economía del sector público. Barcelona: Antonio Bosch.

48. Vega, J. (2007). Análisis del proceso de descentralización fiscal en el Perú. Lima: Pontificia Universidad Católica del Perú.

49. Von Hagen, J. y Dirk Foremny, J. (2012). Federalismo fiscal en tiempos de crisis: Compartir el coste del ajuste. En Informe IEB sobre federalismo Fiscal 2012. Institut d'Economía de Barcelona. Barcelona: IEB.

50. Zas Friz Burga, J. (2001). Procesos de descentralización y recentralización estatales: una aproximación al caso peruano (1821-2000). Revista de Estudios Histórico-Jurídicos, 23. 